BNWh-SA- 3966 CoNf-710601- - 8

\title{
PRODUCTION OF VOIDS IN PURE METALS \\ BY HIGH ENERGY HEAVY ION BOMBARDMENT
}

by

G. L. Kulcinski

J. L. Brimhal1

H. E. Kissinger

\section{THIS DOCUMENT CONFIRMED AS UNCLASSIFIED DIVISION OF CLASSIFICATION DATE $\frac{\text { QHKaha/ } / \text { ST Tamh }}{8 / 6 / 7 /}$}

\section{Pacific Northwest Laboratories \\ Battelle Memorial Institute \\ Richland, Washington}

This report was prepared as an account of work sponsored by the United States Government. Neither the United States nor the United States Atomic Energy Commission, nor any of their employees, nor any of their contractors, subcontractors, or their employees, makes any warranty, express or implied, or assumes any legal liability or responsibility for the accuracy, completeness or usefulness of any information, apparatus, product or process disclosed, or represents that its use would not infringe privately owned rights. 


\section{DISCLAIMER}

This report was prepared as an account of work sponsored by an agency of the United States Government. Neither the United States Government nor any agency Thereof, nor any of their employees, makes any warranty, express or implied, or assumes any legal liability or responsibility for the accuracy, completeness, or usefulness of any information, apparatus, product, or process disclosed, or represents that its use would not infringe privately owned rights. Reference herein to any specific commercial product, process, or service by trade name, trademark, manufacturer, or otherwise does not necessarily constitute or imply its endorsement, recommendation, or favoring by the United States Government or any agency thereof. The views and opinions of authors expressed herein do not necessarily state or reflect those of the United States Government or any agency thereof. 


\section{DISCLAIMER}

Portions of this document may be illegible in electronic image products. Images are produced from the best available original document. 
PRODUCTION OF VOIDS IN PURE METALS

BY HIGH ENERGY HEAVY ION BOMBARDMENT

\author{
by \\ G. L. Kulcinski, J. L. Brimhal.1 and H. E. Kissinger \\ Pacific Northwest Laboratories \\ Battelle Memorial Institute \\ Rich 1 and, Washington
}

INTRODUCTION

The use of high energy ion bombardment to simulate high fluence, high temperature neutron damage in metals has proven to be an unexpected and rewarding new scientific tool. (1-7) This relatively new approach to the study of radiation damage has generated considerable theoretical interest in the effects of extremely high defect production rates. The most notable achievement of this technique is the "preview" of some microstructural defects and dimensional problems ${ }^{(6-8)}$ we may expect to find in metals subjected to 20 years or more of intense radiation damage in future LMFBR's (Liquid Metal Fast Breeder Reactors) or CTR's (Controlled Thermonuclear Reactors). On the other hand, the very feature of this technique which makes it so attractive, namely the unusially high rate of defect production, can prove to be a pitfall to the unwary scientist. Careful analysis of the irradiation temperature and defect production. rate is required before conclusive evidence can be obtained on kinetic processes in metals. The most notable example of this is the shift in "effective" irradiation temperature which can result from defect production rates of $10^{-4}$ or higher. (9)

The potential advantages of using an external beam of energetic ions to accelerate the radiation damage rate by several orders of magnitude were first recognized in 1969 by Nelson and Mazey at Harwe11. (1) They found that they could produce in a matter of hours, a damage state in 316 stainless steel which 
normally required more than a year of fast nuclear reactor irradiation to produce. The initial work was performed with low energy (100 KeV) heavy ions on stainless steel, but these same scientists later found that $20 \mathrm{MeV}$ carbon ions could produce similar results in a much larger volume of sample. (2) They have vigorously pursued this approach by examining the role of inert gases in the production of voids and extended the work to include high fluence damage in $\mathrm{Ni}$.

Two other approaches were immediately taken by scientists at BattelleNorthwest and Atomic International Laboratories in the U.S. The BNW group concentrated on using higher energy (5 - $10 \mathrm{MeV})$ heavy ions, such as $\mathrm{Cu}$, (9) $\mathrm{Ni},(3,10)$ or $\mathrm{Se}{ }^{(7,10)}$ to bombard stainless steel, $\mathrm{Ni}, \mathrm{Mo}, \mathrm{Nb}$ and $\mathrm{Ta}$. These studies confirmed the work of Nelson and Mazey and revealed some rather intriguing three dimensional defect structures and saturation effects in $\mathrm{Ni}$. (7) The AI group chose to pursue the use of $1.4 \mathrm{MeV}$ protons to produce damage in stainless steel and nickel and found equally interesting results. $(5,12)$ Other groups have now investigated the use of protons, (13) deuterons, (14) nitrogen ions ${ }^{(8)}$ and high intensity beams of electrons $(15-17)$ to simulate the high temperature damage produced by neutrons. The results of these latter experiments are currently appearing in the open literature and any extensive review of that work would be premature at this time.

It is the purpose of this paper to briefly review the mechanisms by which heavy $(Z>28)$ ions produce defects in metals and to point out some of the major differences in specific damage rates between electrons, neutrons, light ions, and heavy ions. Recent experimental information on the fluence dependence of the formation of voids in $\mathrm{Ni}$ and the temperature dependence of void formation 
in Mo, TZM and Nb will be given. The effect of pre-injected helium on the formation of voids in nickel will also be discussed. DISPLACEMENT OF ATOMS BY ENERGETIC HEAVY IONS

As a high energy heavy ion passes through a metal, it loses energy by two major processes; electronic and nuclear collisions with the metallic atoms. The electronic interactions result mainly in ionization of the atoms and does not significantly contribute to the forceable ejection of atoms from their equilibrium positions. On the other hand, a large fraction of the nuclear energy transferred in interactions between the incident nucleus and the struck nucleus. results in displaced atoms. Lindhard, et al, $(18,19)$ and Schiott ${ }^{(20)}$ have published rather comprehensive reviews of the factors which govern the rate at which energy is lost in both nuclear and electronic collisions and their theories have been modified to predict the number of displaced atoms produced by incident beams of energetic ions. (4) Only a brief account of the calculation methods is given below.

There are, in reality, three separate problems that must be solved before we can arrive at the final answer of the displaced atom density; the range of the particle must be determined, the rate of nuclear energy loss must be calculated as a funclion of the distance into the solid, and finally, we must convert the nuclear energy loss into a displaced atom density. The Lindhard model assumes that the nuclear and electronic collisions can be treated independently, that the electronic energy loss is proportional to the velocity of the incident ion and that the atoms are randomly placed in the solid, (i.e., it ignores crystallographic effects).

The average range of an energetic ion can be calculated if we know the energy dependence of the nuclear and electronic stopping powers, $(\mathrm{dE} / \mathrm{dX})_{n}$ 
and $(d E / d X)_{e}$, respectively. Calculation of these quantities involves a rather complex approximation of the interaction between incident and struck particles through a screened Thomas-Fermi type potential. The reader is referred to Lindhard, et al, (18) for a more detailed discussion. Assuming that the various stopping powers can be calculated, the average range of the incident particle is then

$$
\bar{R}=\int_{0}^{E} \frac{d E}{\left(\frac{d E}{d x}\right)_{n}+\left(\frac{d E}{d x}\right)_{e}}
$$

Equation 1 gives the total path length of an incident ion into the solid, but we are usualty more interested in the average projected range of that particle into the solid. This latter quantity, $\bar{R}_{p}$, is the perpendicular distance from the incident surface to the final resting place. The projected range can be calculated by

$$
\frac{\bar{R}-\bar{R}_{p}}{R_{p}}=\mu \Psi(E, k)
$$

where $\mu$ is the mass ratio of the struck and incident particles.

$\Psi(E, k)$ is a parametric function of the incident ion energy and the atomic properties of the incident and struck ions through a constant $k$.

Equation 2 allows us to calculate the average projected range of the incident particle, but there is in reality a Gaussian distribution of ranges 
around the average value. We can calculate the distribution of ranges in the normal fashion;

$$
\frac{N}{C}=\frac{1}{\alpha \sqrt{2 \pi}} \exp -\left(\frac{\left(R-\bar{R}_{p}\right)^{2}}{2 \alpha^{2}}\right)
$$

where $\mathrm{N}=$ concentration of stopped ions per $\mathrm{cm}^{3}$.

$C=$ incident fluence of ions per $\mathrm{cm}^{2}$.

$\bar{R}_{p}=$ ave. projected range.

$\alpha^{2} \cong \gamma\left(\bar{R}_{p}\right)^{2} F(k, E, V)$

$\gamma=$ four times the reduced mass ratio of the incident and struck atoms.

$F(k, E, V)$ is a function which depends on the degree of electronic scattering through the constant $k$, the energy $E$ of the incident ion and the form of the scattering potential used; a screened Thomas-Fermi type for this study.

We can now calculate the total amount of nuclear energy transferred to the metal atoms at any given distance into the solid by the formula

$$
S_{n}(x) \cong \int_{0}^{R_{p}} f\left(R_{p}\right) S_{n}\left(R_{p}-x\right) d R_{p}
$$

where $f\left(R_{p}\right)$ is the fraction of incident ions with projected ranges between $R$ and $R+d R$

$S_{n}\left(R_{p}-x\right)$ is the nuclear energy transfer rate, evaluated at $X$ for a particle with projected $R_{p}$. 
The next step is to determine the displaced atom density resulting from the nuclear energy transfer rates calculated from equation 4 . It has been recentiy noted that on $7 y$. $60 \%$ of the energy lost in nuclear collisions results in displaced atoms. (21) This reduction comes about because some of the struck atoms lose energy in "nonproductive" electronic interactions with the surrounding atoms. Therefore, the "productive" energy used to displace atoms is really $0.6 \times \overline{S_{n}(X)}$.

The conversion from nuclear energy transfer to displaced atom density can be made by using a Kinchen and Pease ${ }^{(22)}$ approximation which yields,



where $N(X)$ is the number of atoms displaced per $\mathrm{cm}^{3}$ at a distance

$x$ into the solid.

$E_{d}$ is the displacement energy

$N_{I}$ is the incident ion fluence

The more universal term now being used is the number of times each atom is theoreticalily displaced during the irradiation. This unit, called dpa for displacements per atom, can be obtained from equation 5 by simply dividing by the atomic density, $\mathrm{N}$.

The dpa value at any distance into the solid is then

$$
d p a(X)=\frac{N(X)}{N_{0}}
$$


COMPARISON OF DAMAGE RATES FROM HEAVY AND LIGHT ION BOMBARDMENT

The rate at which defects are produced in a metal is mainly a function of three things; the displacement energy, the specific efficiency for transferring energy in collisions between the incident ions, and the struck atoms, and the flux of particles which can be directed on the solid. In general, heavy ions, such as $\mathrm{Ni}$ or $\mathrm{Ta}$, are several orders of magnitude more efficient in producing damage than are protons and carbon ions. On the other hand, much higher beam currents of the lighter ions are available. A few examples of these generalities will illustrate the point.

Figure 1 shows the relative effectiveness of the more common particles used to produce displacements in a metal like nickel. We see, that each tantalum ion is five times more effective in displacing atoms than is a nickel ion, and 100 times more effective than a carbon ion and more than 5000 times more effective than a proton. This factor rises to $3 \times 10^{6}$ for $14 \mathrm{MeV}$ neutrons and $10^{7}$ for $7 \mathrm{MeV}$ neutrons and to greater than $10^{8}$ for $1 \mathrm{MeV}$ electrons (the latter number is not shown in Figure 1).

The data in Figure 1 can be placed in more perspective by multiplying the damage efficiency by presently attainable beam currents listed in Table I. The data here is taken from the literature and must be considered to be temporary as advances in ion source technology will certainly increase some of the displacement rates in the future. The main limitation on beam currents of the lighter ions is the amount of heat input. For example, we have assumed that a few hundred watts per $\mathrm{cm}^{2}$ is the upper energy input limit for reasonable temperature control of the samples. Above this limit, the temperature uncertainties would render quantitative work on nucleation and growth somewhat 


\section{TABLE I}

\section{CURRENTLY ATTAINABLE FLUXES OF HIGH ENERGY}

PARTICLES USED TO PRODUCE VOIDS IN METALS

Particles

Electrons (1 MeV)

Neutrons ( $>I$ MeV) (EBR-II)

Neutrons (T4 MeV) (Future CTR)

Protons (1 - $2 \mathrm{MeV}$ )

Carbon ions (20 MeV)

Nickel ions (5 - $10 \mathrm{MeV})$

TantaTum Ions (5 - $10 \mathrm{MeV}$ )
Particles $/ \mathrm{cm}^{2} / \mathrm{sec}$

$4 \times 10^{19}$.

$6 \times 10^{14}$

$4 \times 10^{14}$

$6 \times 10^{14}$

$1.2 \times 10^{14}$

$6 \times 10^{13}$

$6 \times 10^{12}$ 
suspect. Figure 2 shows the range of relative displacement rates currently attainable with electrons, neutrons, protons, carbon ions, nickel ions and tantalum ions. The larger beam currents presently attainable for high energy nickel ions gives it a slight edge over the tantalum ions even though tantalum is more efficient in imparting "useful" energy to the lattice. The maximum displacement rates of $1 \mathrm{MeV}$ electrons, $1 \mathrm{MeV}$ protons and $20 \mathrm{MeV}$ carbon ions are roughly 2 orders of magnitude lower than the heavier ions although they are still some 3 orders of magnitude higher than displacement rates in present fast reactors and proposed CTR's. It should be pointed out that all of these techniques are not confined to operate at the maximum damage rates. They could, and most often do, vary the damage rate by several orders of magnitude below the maximum possible:

Figure 1 also illustrates another important distinction between the various ions used for the simulation work, namely, the volume of material in which the displacements occur. In contrast to high. energy neutrón bombardment which produces displacements uniformly throughout the solid, the energetic ions produce damage in a non-homogeneous fashion. Typical damage zones of high energy bombarding particles vary from $5000 \AA$ for $7.5 \mathrm{MeV} \mathrm{Ta}, 1$ micron for $5 \mathrm{MeV} \mathrm{Ni,} 7$ microns for $20 \mathrm{MeV}$ carbon, $10 \mathrm{microns}$ for $1.3 \mathrm{MeV}$ protons and $250 \mathrm{microns}$ for $1 \mathrm{MeV}$ electrons. The increased range of the lighter ions greatly alleviates the specimen prepara-. tion problems although techniques are now available $(10,23)$ to thin even samples bombarded with Ta with a fair degree of accuracy. 
The major disagreement in this field now centers around whether the voids are homogeneous ly $(24-27)$ or heterogeneous $7 y^{(9,16,27-31)}$ nucleated. The homogeneous theories are based on the assumption that voids are formed by the statistical agglomeration of vacancies or in the center of randomly distributed displacement spikes. The heterogeneous nucleation theories assume that gas atoms (either inert elements produced by transmutation or residual elements such as oxygen, nitrogen or hydrogen) are required to stabilize the void embryos no matter how the latter are formed.

Ion bombardment experiments can be tailored to give some insight into the void nucleation mechanisms. For example, unlike neutron irradiation studies, the presence or absence of inert gases in the metal is strictly up to the experimenter. The high defect production rate and the possibility of varying it over several orders of magnitude should prove or disprove theories that are inherently defect production rate sensitive. Finally, by choosing the proper incident particle, such as an electron, one can eliminate displacement spike effects and thereby determine their importance in void nucleation. The present experiments concentrate on the inert gas and rate sensitivity questions. 
PRECIPITATION OF VACAMICIES INTO VOIDS

Thus far we have only considered how the individual vacancies and interstitial atoms are produced. How do theșe defects, especially the vacancies, end up in clusters? The answer to this question is the subject of considerable controversy at the present time and a complete assessment of the situation is not the object of this paper. We will only point out here a few features that most scientists agree on and some of the major points of disagreement as a background for future discussion.

The first point of general agreement is that there must be a supersaturation of vacancies in the metal before voids can be nucleated and grown. Secondly, the supersaturation of vacancies can only produce voids if the vacancies can move to nucleation sites and reduce the amount of recombination. Hence, there is a minimum temperature required during irradiation to form voids. This minimum temperature is approximately $30 \%$ of the absolute melting point and is assumed to be associated with the vacancy migration temperature. There is also a maximum temperature above which the thermal production of vacancies reduces the supersaturation level below that required for void formation and growth. This upper temperature limit is approximately $50 \%$ of the melting point in most metaIs.

The third point of agreement is that because vacancies and interstitials are produced in equat numbers during irradiation, there must be some sinks which preferentialty remove interstitial atoms during irradiation leaving an excess of vacancies in the lattice. The biased sinks are commonily assumed to be dislocations which are either present before irradiation or formed by the precipitation of interstitial atoms into dislocation loops. 
EXPERIMENTAL

Material

The chemical analysis of metal foil used. for this study is shown in Table II. Three millimeter diameter samples were punched from the foil and annealed to the conditions also listed in Tabie II. After annealing, the samples were electropolished to obtain as smooth a surface finish as possible Irradiation

A detailed description of the experimental arrangement used to bombard the samples is given in Reference 10 . Briefly, the $3 \mathrm{~mm}$ samples were held on a heated stainiess steel or tantalum furnace while being bombarded. Each sample was bombarded individually with a maximum of ten samples irradiated per run. The bombarding fluxes are slightly different for each species, but, in general, varied from 1 - 10 microamperes $/ \mathrm{cm}^{2}\left(6 \times 10^{12}\right.$ to $6 \times 10^{13}$ particles $\left./ \mathrm{cm}^{2} / \mathrm{sec}\right)$.

The $\mathrm{Ni}, \mathrm{Cu}$ and $\mathrm{Ta}$ ions were produced from a sputtering source similar to that described by Mueller and Hartig (32) (see also Reference 10). The selenium ions were produced by a diode source. (33) Ideally, one would like to use only $\mathrm{Ni}$ ions to bombard $\mathrm{Ni}$ foil and refractory metal ions, i.e., Ta to bombard $\mathrm{Nb}$ and Mo. However, the low concentrations of heavy ions required to produce reasonable damage ( $210-50 \mathrm{dpa}$ ) resulted in less than $0.1 \%$ impurities at the position of examination. No second phase particles were observed at these levels when metallic ions different than the targets were used.

Some of the well annealed nickel samples were pre-injected with approximately 3 atomic parts per million of helium atoms from the University of Washington Cyclotron. (34) The helium atoms were uniformly distributed in a 25 micron thick layer by a technique described elsewhere. (35) 
TABLE II.

PRE-IRRADIATION PROPERTIES

OF MATERIALS FOR ION BOMBARDMENT STUDIES

Impurity

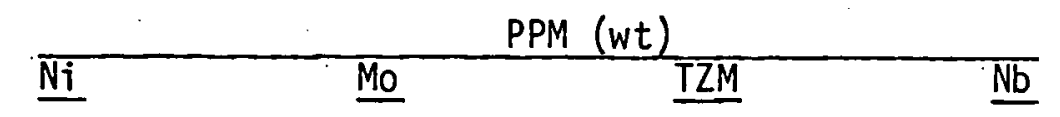

AI

C

$\mathrm{Cd}$

Co

$\mathrm{Cr}$

$\mathrm{Cu}$

$\mathrm{Fe}$

H

$\mathrm{Mg}$

$\mathrm{Mn}$

Mo

N

$\mathrm{Ni}$

0

$\mathrm{Pb}$

Si

$\mathrm{Sn}$

$\mathrm{Ta}$

$\mathrm{Ti}$

V

W

$\mathrm{Zr}$

Pre-irradiation Anneal

Temp ${ }^{\circ} \mathrm{C}$ 700

Time $T_{m}$

Bal.

Vacuum-Torr $<2$

50

0.5

90

1

0.5

5

10

$<0.1$

$<0.1$

$<1$

$<10$

200

$<5$

200

$<10$

$<5$

$<5$

$<2$.

100

0.8

$<1$

$<2$

Bar.

1

$<5$

4.5

$<10$

$<10$

$<5$

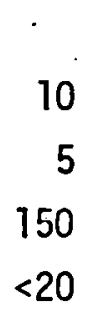

1800

0.5
$\times 10^{-5}$
$<300$

100

30

60

60 .

2

0.8

$<100$

Bal.

. 4-15

90

9

145.

$10-20$

$<300$

20

200

60

5

80

60

$2 \times 10^{-6}$

$1 \times 10^{-5}$

1800

750

$1 \times 10^{0.5}$

0.7
$1 \times 10^{-7}$ 


\section{Examination}

The procedure for thinning the $\mathrm{Ni}$ samples has been described earlier. $(7,23)$ The same general technique was used for the Mo and Nb samples except for different jetting and electropolishing solutions.

Electron microscopy studies were conducted with a Hitachi $200 \mathrm{~F}$ electron microscope. The average void size was determined from $160,000 \times$ photographs while the number density of voids was obtained by noting the thickness of the foil from stereo analysis or by the interference fringe technique. All volume changes are calculated from the experimentally determined void size and number density.

Determination of Displacement Density

The displacement density was calculated by a method described earlier (4) and Figures 3 and 4 show typical calibration curves for $\mathrm{Ni}$ and $\mathrm{Nb}$, respectively. The calibration curve for Mo is similar to Figure 4 and is not included here. Note that although the dpa values per incident particle are much higher for Ta than $\mathrm{Ni}$ or $\mathrm{Se}$, the damage for $\mathrm{Ta}$ ions occurs over a much shorter range. This shorter range makes the determination of the penetration distance more critical and results in a much higher error band for dpa estimates. 


\section{RESULTS}

\section{Nickel}

Both pure and helium doped samples were irradiated at $525{ }^{\circ} \mathrm{C}$ with $5-6$ - MeV Ni ions and $8-11 \mathrm{MeV}$ Se ions. The displacement densities ranged from 0.4 to $480 \mathrm{dpa}$. Voids were found in all of the samples and Table III lists the average void size, number density and calculated volume change for each sample.

Figure 5 graphically displays the effect of increasing displacement damage on the average void size. The average diameter rises from approximately $100 \AA$ at $0.4 \mathrm{dpa}$ to approximately $300 \AA$ at $67 \mathrm{dpa}$. Above $100 \mathrm{dpa}$ there appears to be a stight reduction in the average void size. It is also worth noting that there was Tittle, if any, significant difference between samples that were pre-injected with helium and those which were irradiated without helium. There also is no significant difference between samples which were irradiated with $\mathrm{Ni}$ ions and those bombarded with Se ions. The morphology of the voids in all samples is consistent with $[00\}$ truncated $\{111\}$ octahedra similar to that determined by other studies $(36,37)$ except at the highest damage states where they appear to be more like $\{100\}$ cubes.

Figure 6 shows that the average void density rises from $i 3 \times 10^{14} / \mathrm{cm}^{3}$ at 0.4 dpa to a constant value of $i 3-4 \times 10^{15} / \mathrm{cm}^{3}$ over the entire $2-480 \mathrm{dpa}$ range except for the two highest dpa points of the Se bombarded samples. There is no noticeable difference between pure and helium doped samples or samples bombarded with $\mathrm{Ni}$ or Se ions over the majority of the damage range. This similarity is quite evident in Figure 7 where we compare the microstructure of doped and undoped nickel bombarded samples and an undoped selenium bombarded 
TABLE III

VOID DATA ON NICKEL BOMBARDED AT $525^{\circ} \mathrm{C}$
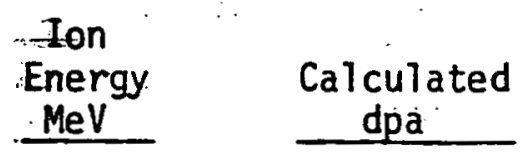

$\rightarrow$ Ave.


Ave. Vojd Density

$\times 1015 / c c$

A

Cazculated
Swelling
$\%$

$\mathrm{Ni} \rightarrow \mathrm{Ni}, 3$ appm Helium

$\begin{array}{cc}5 & 1 \\ 5 & 4.4 \\ 5 & 6.5 \\ 5 & 10 \\ 5 & -25 \\ 5 & 58 \\ 6 & 67 \\ 5 & 360 \\ 5 & 480\end{array}$

$\mathrm{Ni}+\mathrm{Ni}$, No Pre-injected Helium

$\begin{array}{cc}6 & 0.43 \\ 6 & 1.3 \\ 6 & 6 \\ 6 & 44\end{array}$

135

140

140

265

1.1

2:0

2.9

3.2

3.5

3.3

2.7

4.2

4.0
0.07

0.19

0.46

0.67

1.7

2.7

4.0

3.4

3.7

$\underline{\mathrm{Se}} \rightarrow \mathrm{Ni}$, No Pre-injected Helium

$\begin{array}{lllll}11 & 0.47 & 90 & 0.30 & 0.012 \\ 11 & 2 & 70 & 1.7 & 0.05 \\ 11 & 2.3 & 120 & 2.7 & 0.24 \\ 8 & 12 & 210 & 3.6 & 1.7 \\ 8.8 & 47 & 4.0 & 4.1 \\ 8.8 & 95 & 270 & 7.6 & 4.2 \\ 6 & 400 & 220 & 14^{\star} & 4.4\end{array}$

*Calculated from superlattice of fcc voids with $660 \AA$ lattice constant. 
sample. The average void size is about the same in all three samples as is the number density (taking into account the different thicknesses of foil that were examined).

The calculated volume change is shown in Figure 8 . This figure reveals that the swelling increases from $20.02 \%$ at 0.4 dpa to $\sim 4 \%$ at 40 dpa rough $7 y$ as the $3 / 2$ power of the dpa values. Above $40 \mathrm{dpa}$ the volume change seems to have saturated at $4-5 \%$ up to $480 \mathrm{dpa}$.

At 360 - $480 \mathrm{dpa}$ the voids developed into a rather interesting microstructure in both helium doped and undoped samples. Figure $9^{\circ}$ shows the voids viewed in a $\{111\}$ and a $\{110\}$ foil orientation after Se bombardment, and Figure 10 shows the voids from a [100] direction in $\mathrm{Ni}$ ion bombarded,helium doped nickel. These figures show that the voids are not randomly placed, but rather tend to line up in rows parallel to the $\langle 100\rangle$ directions. Further analysis of this structure reveals that the voids are actually aligned in a fcc superlattice with a lattice spacing of $660 \AA$. Figure 11 shows the comparison of a $\{110\}$ view to an artist's drawing of what the corresponding fcc structure would look like. The voids in the ion bombarded sample are actually $\{100\}$ truncated $\{111\}$ octahedra, so they do not have the exact appearance characteristic of perfect octahedra viewed. in a $\{110\}$ foil orientation.

Molybdenum and Niobium

Pure Mo, TZM and Nb: samples were bombarded with $5 \mathrm{MeV} \mathrm{Ni}$ ions over the temperature range of $650-1000{ }^{\circ} \mathrm{C}$ and niobium was irradiated with $7.5 \mathrm{MeV} \mathrm{Ta}$ ions at $900^{\circ} \mathrm{C}$. In the nickel experiment, the displacement density was held constant at approximately 5 dpa while the temperature was varied. The results of the microstructural examination are listed in Table IV. Voids were found in all samples after 800,900 and $1000{ }^{\circ} \mathrm{C}$ irradiations, but only dislocation loops 
TABLE IV.

VOID DATA ON ION BOMBARDED Mo, TZM AND Nb (a)

Irradiation

Temp. ${ }^{\circ} \mathrm{C}$

$650^{(b)}$

800

900

1000
Ave.

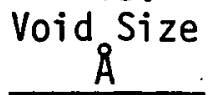

Ave. Void Density

$\times 10^{16} / \mathrm{cc}$
Calc. Swelling $\%$

\section{Molybdenum}

${ }_{N D}(c)$
50
75
120

ND

5.2

4.7

0.53

0.34

1.0

0.48

Niobium

$\begin{array}{lrr}650^{(b)} & \cdots & \text { ND } \\ 700 & & \text { ND } \\ 800 & & 45 \\ 900(d) & & 220 \\ 900 & & 200 \\ 1000 & & 350\end{array}$

ND

ND

6 .

0.15

0.24

0.018

$-$

0.29

0.83

1.0

0.34

\section{TZM}

800
900
1000

60

3.2

1.6

0.36

80

0.36

0.43

0.22

(a) Damage leve 1 i 5 dpa produced by $5 \mathrm{MeV} \mathrm{Ni}$ ions except where indicated.

(b) $6 \mathrm{MeV} \mathrm{Ni}$ ions.

(c) ND - None detected.

(d) $7.5 \mathrm{MeV} \mathrm{Ta}$ ions, is dpa 
were found in Mo after the $650^{\circ} \mathrm{C}$ irradiation and in $\mathrm{Nb}$ irradiated at 650 and $700{ }^{\circ} \mathrm{C}$. Examples of the voids are shown in Figures 12 and 13.

The general effect of increasing irradiation temperature was to increase the average void size and reduce the average void density in both samples. There was little difference between Nb, TZM and Mo after the $800{ }^{\circ} \mathrm{C}$ irradiation, but the average void size in Nb was approximately 3 times that in Mo and TZM samples after the 900 and $1000^{\circ} \mathrm{C}$ studies. The increased void sizes in Nb are accompanied by reduced number densities so that the total number of vacancies in the voids (i.e., the swelling) is not significantly different at the three temperatures. Figure 14 shows that the swelling for all three materials follows the characteristic bell shaped curve found in other neutron irradiated metals and alloys.

The morphology of the voids is difficult to determine in the Mo and TZM samples because of the small average size. The voids in niobium, especially after the $1000{ }^{\circ} \mathrm{C}$ irradiation, appear to take on the morphology of a truncated $\{100\}$ cube. This shape is evident in Figure 15 which shows the voids viewed in \{111\} and $\{110\}$ foil orientations. It appears that there is a sight amount of truncation on the $\{110\}$ faces of the cubes.

Finally, a non-random alignment of voids was also found in Nb irradiated at $800^{\circ} \mathrm{C}$. Figure 16 shows this alignment when viewed in a $\{111\}$ foil orientation. The rows of voids, parallel to <112> directions, suggest a bcc superlattice of voids in contrast to the fcc superlattice in $\mathrm{Ni}$. The "lattice" constant of this array is determined to be $350 \AA$ which would predict a void density (2 voids per bcc unit cell) of $4.7 \times 10^{16} / \mathrm{cm}^{3}$. This agrees quite well with the value of $6 \times 10^{16} / \mathrm{cm}^{3}$ determined by measuring the number of voids in a random orientation. The volume calculations in the latter case were made by noting the thickness 
indicated from stereo measurements in an area of photograph which contained the voids. No aligned voids were found in $\mathrm{Nb}$ at higher temperatures nor was there any conclusive evidence for aligned voids in Mo or TZM at $800{ }^{\circ} \mathrm{C}$. 
DISCUSSION

It is fairly obvious from the present study that inert gas atoms such as helium are not necessary for the formation of voids in heavy ion bombarded $\mathrm{Ni}$, Mo, TZM, or $\mathrm{Nb}$. This point is reinforced by the fact that pre-injection of part of the nickel samples with 3 appm of helium atoms did not significantly a!ter the size, number density or volume change when compared to the undoped samples. These results are in agreement with those of Nelson and Mazey ${ }^{(1)}$ on stainless steel although the latter investigators did find a significant effect when the pre-injected helium levels exceeded $10 \mathrm{appm}$. The higher helium concentrations increased the number density, but reduced the average size of the voids. Bloom and Steigler ${ }^{(8)}$ found much the same result from neutron irradiated stainless steel that contained pre-injected helium levels of 20 appm. The latter two experiments suggest that the helium level in our tests may have been too low to show a significant effect on the nucleation of voids.

The present results, and those of Nelson and Mazey, (1) do not agree with the work of Norris. (15) He found that no voids could be produced in "pure" nịcke1 during 1 MeV electron bombardment, but voids did appear when identical samples were irradiated after pre-injection with approximately 70 appm of argon atoms. He concluded from these experiments that 1) displacement spikes are not required for void nucleation because only mono- or divacancies are produced by $1 \mathrm{MeV}$ electrons, and 2) that gas atoms are required for nucleation of voids. The inference from this $(15)$ and later studies $(16)$ is that inert gas atoms are essential for void nucleation, but Urban ${ }^{(17)}$ has recently shown that oxygen may play an important role. Urban's experiment was also conducted wi th high energy electrons so as to eliminate the displacement spike effects. He found 
that voids could be formed in "pure" (non-inert gas injected) nickel if the samples were allowed to oxidize before bombardment. It is logical to conclude from this study that residual gases, such as oxygen, could act as the nucleating site for a void or in some manner stabilize void embryo. Urban's experiment also rules out the requirement that inert gas atoms are essential for nucleation a) though it is entirely possible that inert gas atoms along with other impurities could nucleate voids.

There are ample number of gas atoms in the present samples to act as nuclei for voids even though relatively "pure" starting materials were used. For example, the residual gas concentration $(0+N+H)$ ranges from 100 appm in Mo to $200 \mathrm{appm}$ in $\mathrm{Ni}$ and to as high as $1000 \mathrm{appm}$ in $\mathrm{Nb}$ and TZM. If all of the gas atoms were divided evenly among the highest number density of voids in each sample, we would still have approximately 100 per void in Mo, and up to 1000 per void in $\mathrm{Ni}, \mathrm{Nb}$ and TZM.

It is apparent that more attention must now be paid to the amount of impurity gases in metals. Future studies with extremely high purity, degassed samples will help in establishing the true role of gas atoms in the production of voids.

It is worthwhile at this point to compare the swelling observed in the heavy ion bombarded nickel samples to that obtained from neutron irradiation. Figure 17 shows results from ANL, $(40)$ PNL, $(37,40)$ WADCO, $(41,42)$ and ORNL $(43)$ studies in a rather wide range of temperatures $\left(370-500^{\circ} \mathrm{C}\right)$. It can be seen that the neutron induced swelling is in good agreement with the heavy ion work even though the helium varies by more than a factor of 200 in the neutron irradiated samples. No particular effort was made to control the gaseous impurity levels of neutron 
irradiated samples, so it is quite possible that they contained as much or more residual gas atoms than the present high purity nickel which could provide ample nucleation sites.

The agreement in Figure 16 is also quite significant considering that the displacement rates were approximately 4 orders of magnitude different.

Bullough and Perrin (9) predict that the major effect of the higher displacement rates associated with the heavy ion work is to lower the "effective" Irradiation temperature. They predict that a high damage rate experiment will produce swelling comparable to a lower temperature neutron experiment. The amount of temperature shift is:

$$
\Delta T=T_{i}^{2} \frac{k}{E_{v}} \ln \frac{K_{i}}{K_{n}}\left[\frac{1}{1+\frac{T_{i}^{K}}{G} \ln \frac{K_{i}}{K_{n}}}\right]
$$

where $T_{i}=$ temperature of the ion bombardment

$k=$ Boltzmann's constant

$E_{v}=$ diffusion energy for vacancies

$K_{j}=$ defect production rate during ion bombardment

$K_{n}=$ defect production rate during neutron irradiation

For example, a $525{ }^{\circ} \mathrm{C}$ irradiation of $\mathrm{Ni}$ with $\mathrm{K}_{n}=10^{-6}$. gives $\Delta T=148{ }^{\circ} \mathrm{C}$ for $K_{i}=10^{-2}$ or $\Delta T=117^{\circ} \mathrm{C}$ for $K_{i}=10^{-3}$. This means that the present work shouid. be comparable to neutron irradiation studies in the $380-410{ }^{\circ} \mathrm{C}$ range, not too far from where most of the data in Figure 14 is obtained. Brimhall, et al, (40) also show that the swelling in neutron irradiated nickel is not too sensitive to the irradiation temperature in the $400-500{ }^{\circ} \mathrm{C}$ range so that it is reasonable that the shift in effective temperature will not be too serious. Such comparisons 
are not expected to be valid near the temperature threshold for swelling in metals because Bullough's ${ }^{(9)}$ model neglects recombination effects. One must be very careful about drawing conclusions from ion bombardment experiments conducted in the temperature region where recombination is important.

The tendency for voids to form three dimensional lattice structures in $\mathrm{Nb}$ and $\mathrm{He}$ doped nickel during nickel ion bombardment is consistent with previous work on selerium bombarded nickel, ${ }^{(7)}$ nitrogen bombarded Mo and TZM, $(8,44)$ and neutron irradiated Mo and $\mathrm{Nb} .{ }^{(45)}$ The superlattices in all of these studies are identical to the metal crystal lattice, i.e., fcc in $\mathrm{Ni}$, bcc in Nb, Mo and TZM.

There is no obvious reason for this behavior at the present time except the possibility that the voids are attempting to minimize the total strain energy in the solid induced by such large swelling. Kissinger ${ }^{(46)}$ has found that there is a strain field associated with voids which can be detected by measuring the $x$-ray line broadening. It is possible that the long range interaction between these strain fields will determine whether or not voids shrink or grow on certain periodic positions in the samples.

It has also been suggested ${ }^{(44)}$ that the anisotropy of the crystal lattice could initiate such an effect. This is in agreement with the fact that $\mathrm{Ni}$, $\mathrm{Nb}$, and Mo have rather high anisotropy factors. (47) One would expect on this basis that voids in more isotropic metals, like $A 1$ or $W$, would not form superlattices. This is consistent with observations by Packan ${ }^{(48)}$ who has reported swelling in $A 7$ of $7.5 \%$ with no evidences of void alignment. However, the evidence for the exact mechanism of alignment is too meager to draw any definite conclusions at the present time. 
The effect of bombarding temperature on swelling in pure Mo is in good agreement with neutron irradiation of identical stock material ${ }^{(40)}$ except for the lowest temperature sample. The fact that no voids were found at $650^{\circ} \mathrm{C}$ in Mo, a temperature at which voids are found in' neutron irradiated Mo, $(40)$ is expected because of the previously mentioned effective temperature shift. The calculated shift is approximately $140{ }^{\circ} \mathrm{C}$ for the $650{ }^{\circ} \mathrm{C}$ ion bombardment. Thus far, no voids have been found in neutron irradiation of Mo at $510{ }^{\circ} \mathrm{C}$. The similarity of swelling in the Mo and $\mathrm{Nb}$ samples was expected because the irradiations were conducted at roughly the same homologous temperatures. The rather large void size in $\mathrm{Nb}$ after the 900 and $1000{ }^{\circ} \mathrm{C}$ irradiations was rather unexpected but there is little high temperature neutron data with which to compare these results. It is significant that the total swelling (i.e., vacancies captured by voids) is roughly the same in the Mo and Nb samples.

The slightly reduced swelling in the TZM samples compared to the pure Mo appears to be mainly due to the factor of $2-3$ lower void density in the TZM. This implies that the nucleation sites are not as numerous. If the total residual gas content is the controlling factor for nucleation, then one would expect more voids in TZM because it contains approximately 10 times more gas (Table II). However, the addition of $\mathrm{Ti}$ and $\mathrm{Zr}$ to the Mo could effectively getter the excess gas in solution and reduce the amount available for nucleation, thereby reducing the swelling.

The fact that approximately the same results (in terms of voids) were obtained from $\mathrm{Ni}$ and $\mathrm{Ta}$ bombardment of $\mathrm{Nb}$ at $900^{\circ} \mathrm{C}$ is important because it shows that a few hundred appm of nickel impurity atoms are not significantly affecting the nucleation process. It is expected that there will be essentially no impurity effects of $\mathrm{Ta}$ in $\mathrm{Nb}$ because of their complete mutual solubility and similar 
chemical properties. (49) Even though it appears that we could use $\mathrm{Ni}$ or $\mathrm{Ta}$ ions for bombardment of refractory metals, all future work will probably be conducted with the Ta ions. 


\section{CONCLUSIONS}

1. Helium gas is not required for the formation of voids in $\mathrm{Ni}, \mathrm{Mo}, \mathrm{Nb}$, and TZM.

2. An increase in the displacement rate in $\mathrm{Ni}$ by 4 orders of magnitude over neutron irradiation does not significantly change the void induced swelling when the shift of the effective temperature is taken into account.

3. Void induced swelling saturated at approximately $4-5 \%$ in $\mathrm{Ni}$ which is bombarded with heavy ions at $525{ }^{\circ} \mathrm{C}$ to more than approximately $50 \mathrm{dpa}$.

4. Voids form a three dimensional superlattice in $\mathrm{Ni}$ and $\mathrm{Nb}$ which is consistent with the crystal structure of the lattice. Doping $\mathrm{Ni}$ with helium atoms does not alter the tendency for alignment.

5. There is little difference between void induced swelling in Mo or Nb over the $800-1000{ }^{\circ} \mathrm{C}$ range at approximately $5 \mathrm{dpa}$. The swelling in TZM over the same temperature range is slightly less than $\mathrm{Mo}$ and $\mathrm{Nb}$. 
ACKNOWLEDGEMENTS

The authors would like to acknowledge the invaluable assistance of $\mathrm{Mr}$.

J. L. Humason and D. H. Chambers for the preparation of the electron microscopy samples and the tedious job of measuring and counting voids. We also wish to thank Mr. W. Powers of Ion Physics Corporation for his help during the heavy ion bombardments and Mr. Ken Garr of Atomics International for injecting the samples with helium. 


\section{REFERENCES}

1. R. S. Nelson and D. J. Mazey, in Radiation Damage in Reactor Materials, Symposium Proceedings, Vienna, Austria, June 2-6, 1969, Vol. II, p. 157.

2. R. S. Nelson, D. J. Mazey and J. A. Hudson, J. Nuc. Mat., 37: 1 (1970).

3. G. L. Kulcinski, J. J. Laidler and H. R. Brager, "Irradiation Effects on Structural Alloys for Nuclear Reactor Applications," ASTM-STP-484. (1970) p. 405.

4. G. L. Kulcinski, D. G. Doran and J. J. Laidler, Rad. Effects, 7: 195, (1970).

5. D. W. Keefer, H. H. Neely, J. C. Robinson, A. G. Pard and D. Kramer, "Irradiation Effects on Structural Alloys for Nuclear Reactor Applications," ASTM-STP-484 (1970) p. 332.

6. D. J. Mazey, J. Nucl. Mat., 35: 60 (1970).

7. G. L. Kulcinski, J. L. Brimhall, H. E. Kissinger, J. Nuc. Mat., To be published.

8. J. H. Evans, Nature, 229: 403 (1971).

9. R. Bullough and R. C. Perrin, "Irradiation Effects on Structural Alloys for Nuclear Reactor Applications," ASTM-STP-484 (1970) p. 317.

10. G. L. Kulcinski, A. B. Wittkower and G. Ryding, Nuc. Instr. and Methods, 91: (1971).

11. G. L. Kulcinski, J. L. Brimhall and H. E. Kissinger, Trans. Amer. Nuc. Soc., 13, No. 2, 555 (1970).

12. H. H. Neely and K. Herschback, Bu11. Am. Phys. Soc., 15: 775 (1970).

13. J. Donhowe, University of Wisconsin, Private Communication.

14. S. D. Harkness and F. L. Yaggee, ANL-766, 1970, p. 144. 
15. D. I. R. Norris, Phil. Mag., 23: 135 (1971).

16. D. I. R. Norris, RD/B/N1879, 1971.

17. K. Urban, Phys. Stat. Sol. (a) 3: K167 (1970)

18. J. Lindhard, M. Scharff and H. E. Schiott, Mat. Fys. Medd. Dan. Vid. Selsk:, 33: No. 14 (1963).

19. J. Lindhard, V. Nielsen, M. Scharff and P. V. Thomsen, Mat. Fys. Medd. Dan. Vid. Selsk., 33: No. 10 (1963).

20. H. E. Schiott, Mat. Fys. Medd. Dan. Vid. Selsk., 35: No. 9 (1966).

21. D. G. Doran and G. L. Kulcinski, To be published. Rad. Effects.

22. G. H. Kinchen and R. S. Pease, "Reports on Progress in Physics," Vol. 18,1955, p. 1 .

23. H. R. Brager, H. E. Kissinger and G. L. Kulcinski, Radiation Effects 5: $281(1970)$.

24. S. D. Harkness and C. Y. Li, in Radiation Damage in Reactor Materials, Symposium Proceedings, Vienna, Austria, IAEA, , 1969, Vol. II.

25. H. W. Wiedersich, in Second International Conference on the Strength of Metals and Alloys, Pacific Grove, California, ASM, 1970, p. 784.

26. J. R. Beeler, in Radiation Damage in Reactor Materials, Vienna, Austria, IAEA, 1969, Vol. II, p. 3.

27. T. T. Claudson, J. L. Straalsund, J. J. Holmes and H. R. Brager, in Radiation Damage in Reactor Materials, Vienna, Austria, IAEA, 1969, Vol. II, p. 165.

28. R. Bullough and R. C. Perrin, in Radiation Damage in Reactor Materials, Vienna, Austria, IAEA, 1969, Vol. II, p. 233.

29. R. Butlough and R. C. Perrin, AERE-R-TP-375.

30. E. E. B100m, ORNL-4580, 1970. 
31. J. H. Shively, in Radiation Damage to Reactor Materials, Vienna, Austria, IAEA, 1969, Vol. II, p. 253.

32. M. Mueller and G. Hortig, IEEE, Trans. Nucl. Sci., NS-16, 1969, p. 38.

33. R. P. Bastide, N. B. Brooks, A. B. Wittkower, P. H. Rose and K. H. Purser, IEEE, Trans. Nucl. Sci., NS-12, 1961, p. 776.

34. We are indebted to Mr. K. Garr from Atomics International for preinjecting the samples with helium.

35. D. Kramer, H. R. Brager, C. G. Rhodes and A. G. Pard, J. Nuc. Mat., 25: $121(1968)$.

36. J. L. Brimhall and B. Maste1, J. Nuc. Mat., 29: 123 (1969).

37. G. L. Kulcinski, B. Mastel and H. E. Kissinger, Acta Met., 19: 27. (1971).

38. E. E. B10om and J. 0. Stiegler, J. Nuc. Mat., 36: 331 (1970).

39. R: V. Strain, ANL-7776, 1970.

40. J. L. Brimha17, H. E. Kissinger and G. L. Kulcinski, This Conference.

41. J. J. Holmes, Trans. Am. Nucl. Soc., 12: 117 (1969).

42. J. L. Straalsund, unpublished data.

43. J. 0. Stiegler, To be published.

44. J. H. Evans, AERE-R-6647, 1971.

45. F. W. Wiffen, This Conference.

46. H. E. Kissinger, Unpublished data.

47. J. P. Hirth and J. Lothe, Theory of Dislocations, p. 761, McGraw-Hi11, New York, 1968.

48. N. H. Packan, ORNL-TM-3109.

49. D. E. Williams and W. H. Pechin, Trans. ASM., 50:1081 (1958). 


\section{FIGURE CAPTIONS}

1. Displacement Damage Effectiveness for Various Energetic Particles in Nickel

2. Displacement Rates Currently Available by Energetic Particle Bombardment of Nickel

3. Displaced Atom Density for $\mathrm{Ni}$ and Se Ions in Nickel

4. Displaced Atom Density for $\mathrm{Ta}$ and $\mathrm{Ni}$ ions in Niobium

5. Effect of Displacement Damage at $525{ }^{\circ} \mathrm{C}$ on the Average Void Size in Nickel

6. Effect of Displacement Damage at $525{ }^{\circ} \mathrm{C}$ on the Number Density of Voids in Nickel.

7. Voids in Nickel After $525^{\circ} \mathrm{C}$ Bombardment

8. Swelling in Nickel After $525^{\circ} \mathrm{C}$ Heavy Ion Bombardment

9. Void Alignment in Nickel After Se Ion Bombardment

10. Void Alignment in Helium Doped Nickel After Ni Ion Bombardment

11. Face Centered Cubic Superlattice of Voids in Nickel

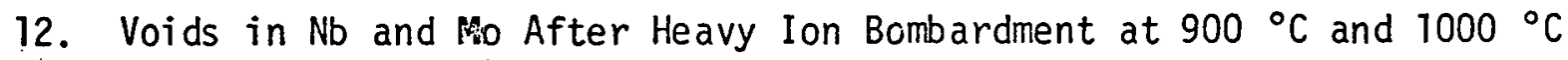

13. Effect of Irradiation Temperature on the Microstructure of TZM

14. Effect of Irradiation Temperature on Swelling in Heavy Ion Bombarded Mo, TZM and $\mathrm{Nb}$

15. Morphology Determination of Voids in Nb After $1000{ }^{\circ} \mathrm{C}$

16. Aligned Voids in $\mathbb{N b}$ After $800{ }^{\circ} \mathrm{C}$ Irradiation

17. Comparison of Neutron Induced Swelling in Nickel to that Found in the Present Study 


\section{DISPLACEMENT EFFECTIVENESS FOR VARIOUS PARTICLES IN NICKEL}

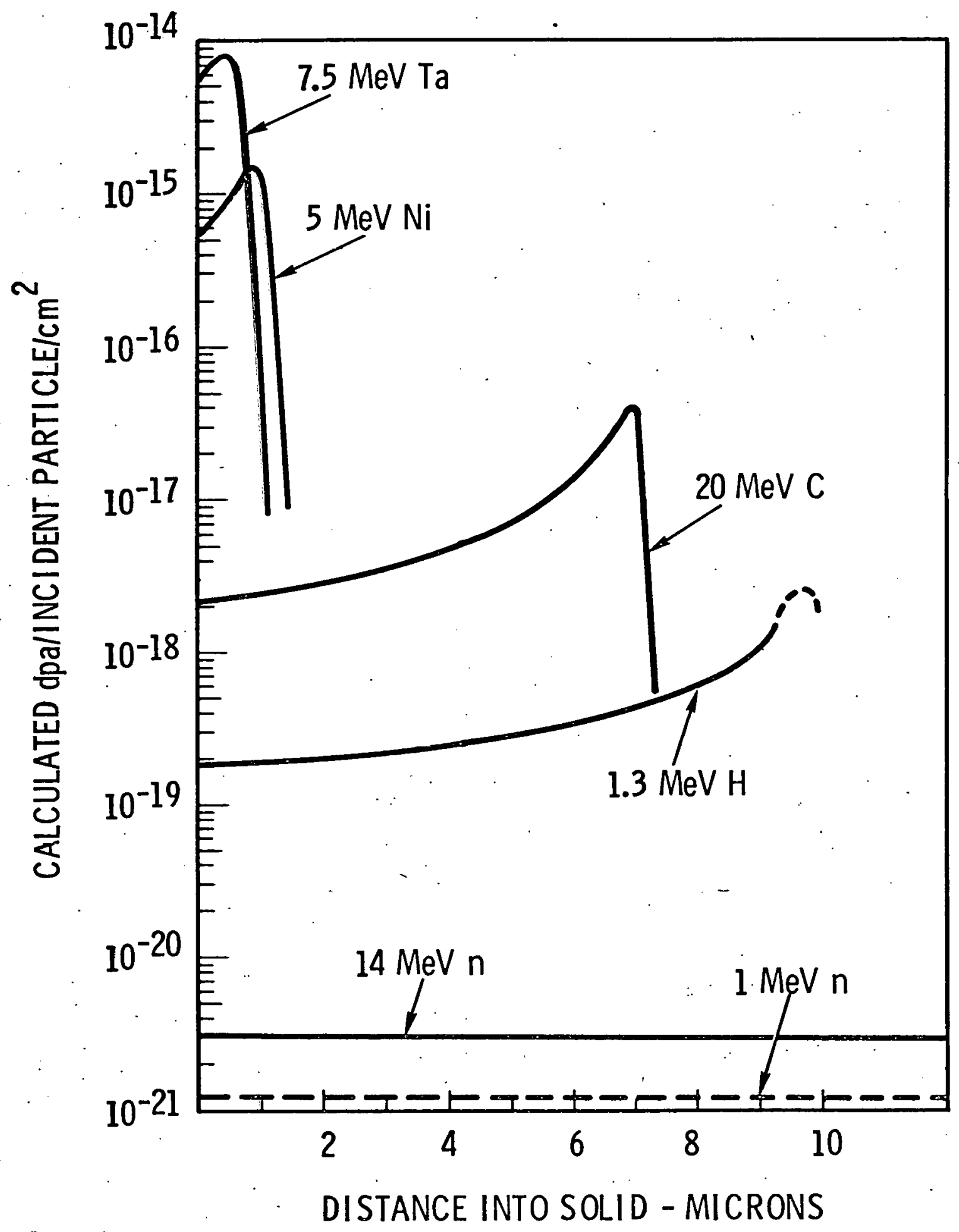




\section{RANGE OF DISPLACEMENT RATES DURIAG IRRADIATION OF NICKEL}






\section{DISPLACED ATOM DENSITY FOR Se AND NI IONS IN NICKEL METAL}

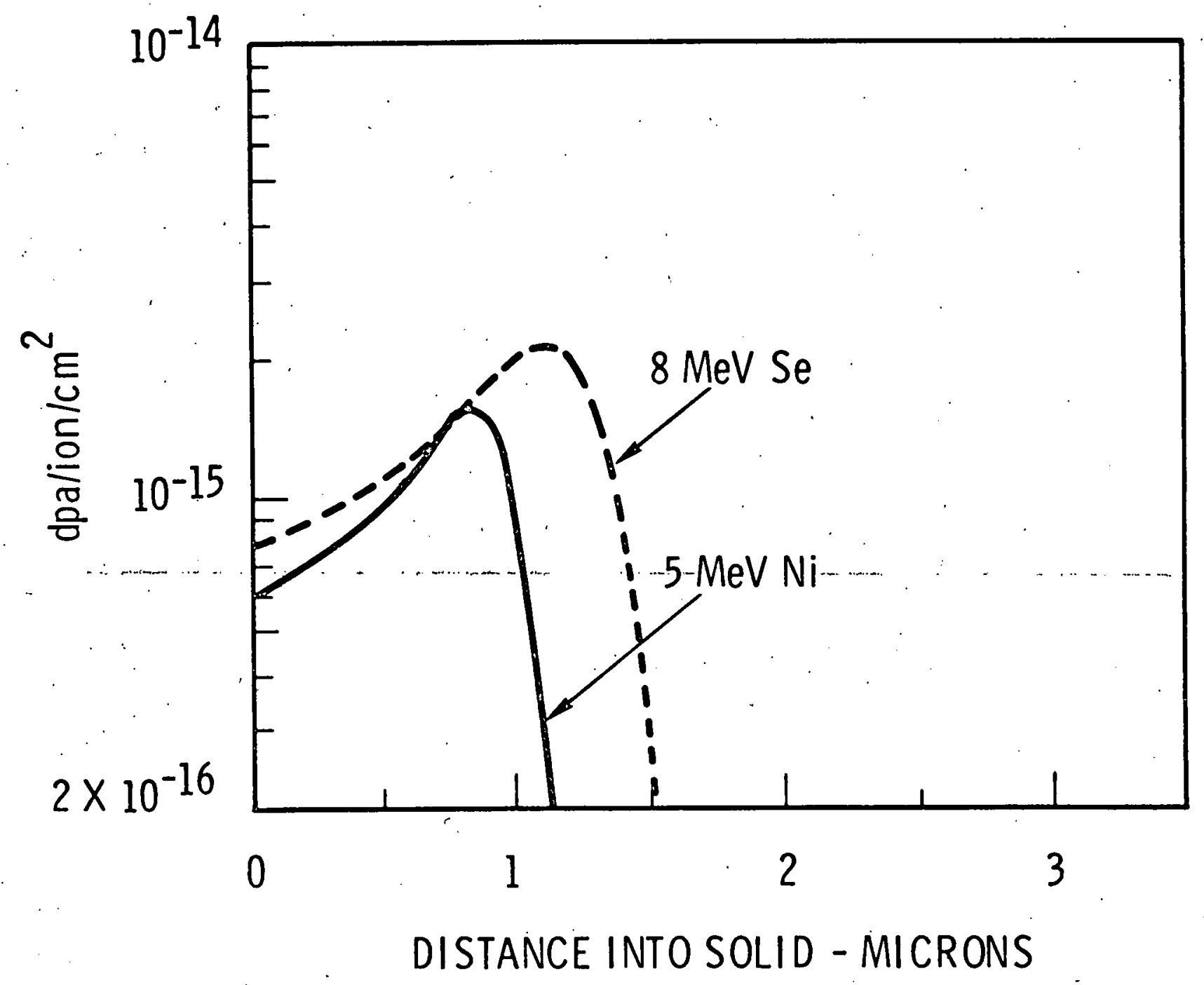




\section{DISPLACED ATOM DENSITY FOR}

Ta AND NI IONS INA MO MAETAL

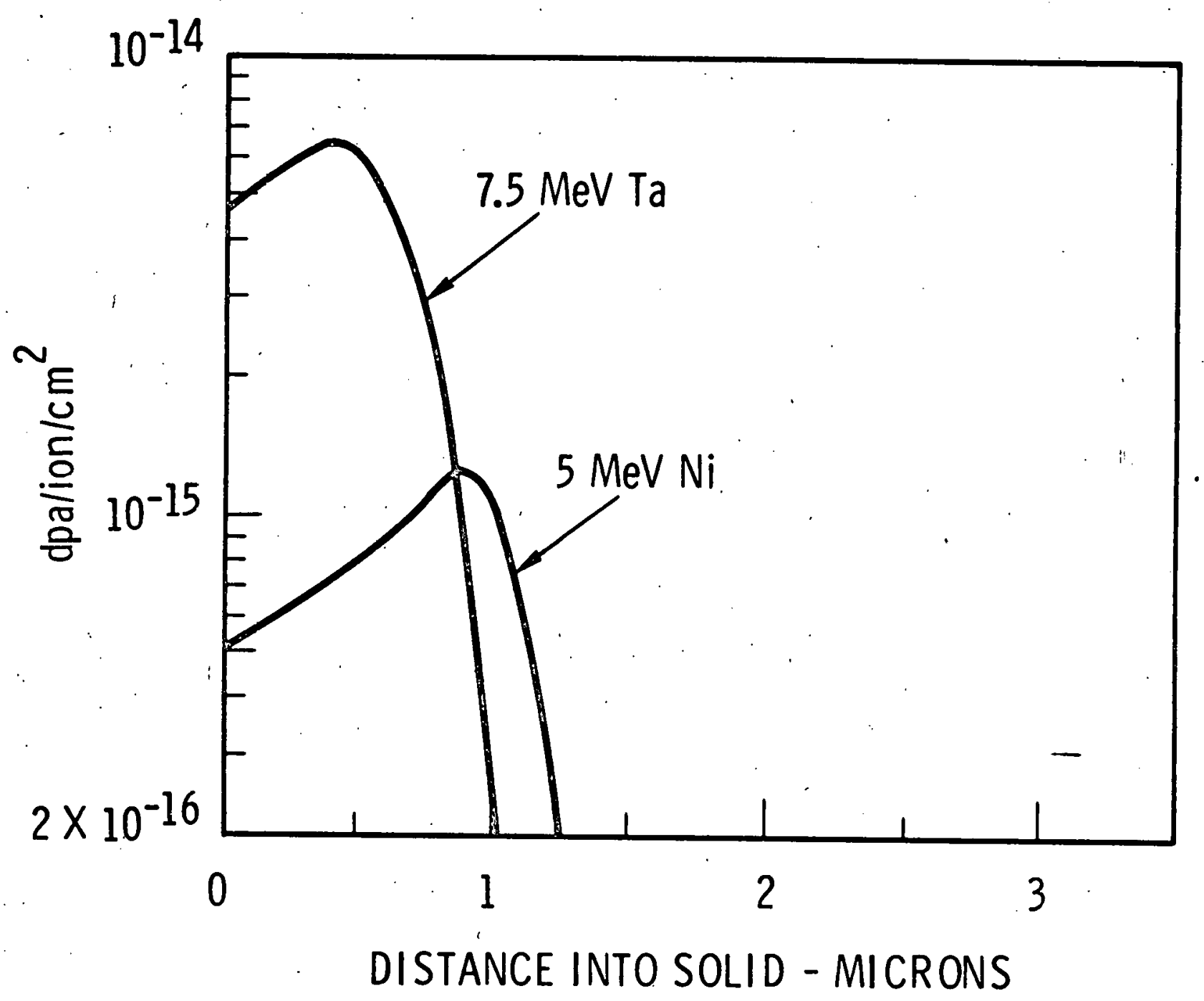




\section{AVERAGE VOID SIZE IN NICKEL BOMBARDED AT $525^{\circ} \mathrm{C}$}






\section{AVERAGE VOID DENSITY IN NICKEL BOMBARDED AT $525^{\circ} \mathrm{C}$}

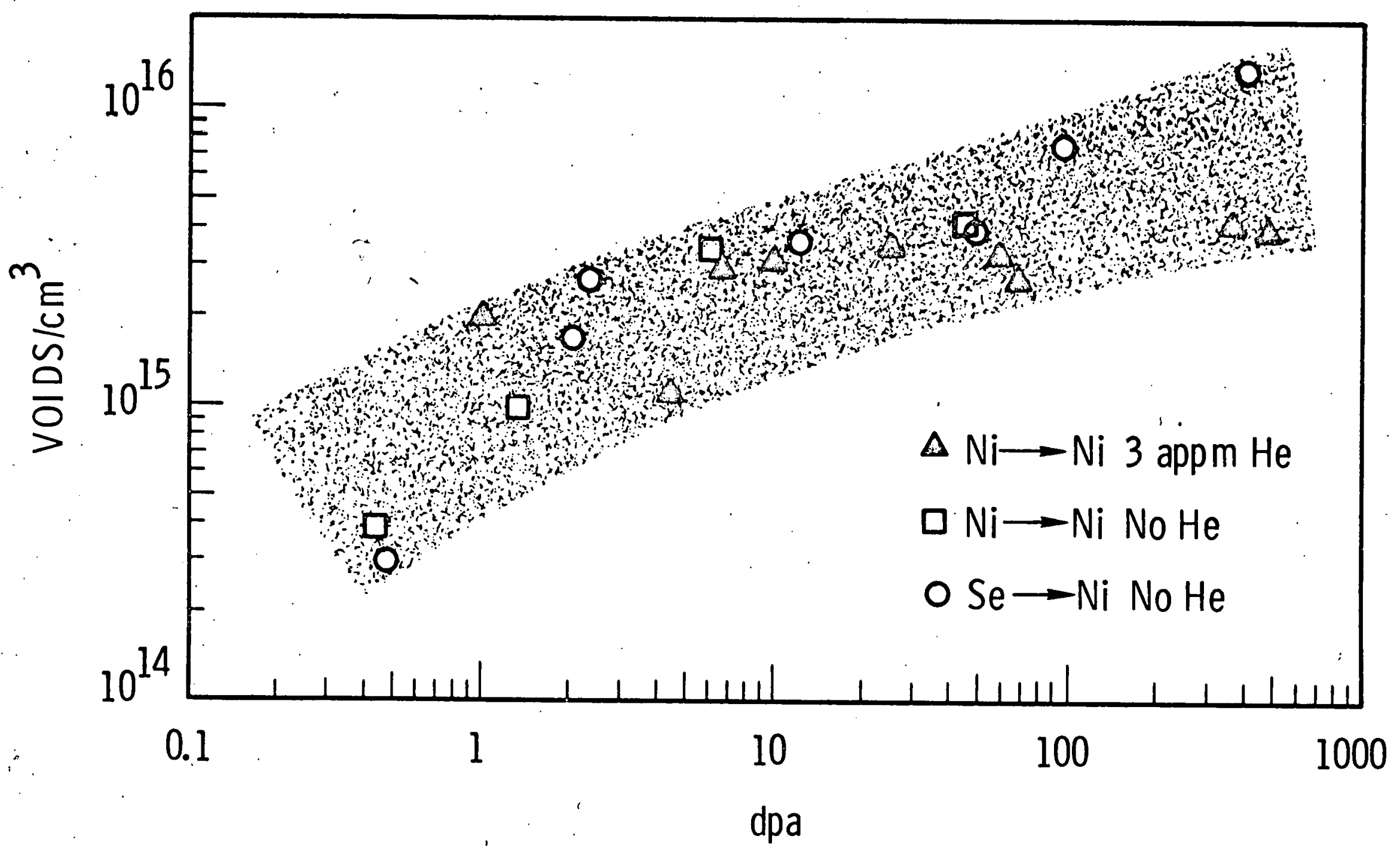




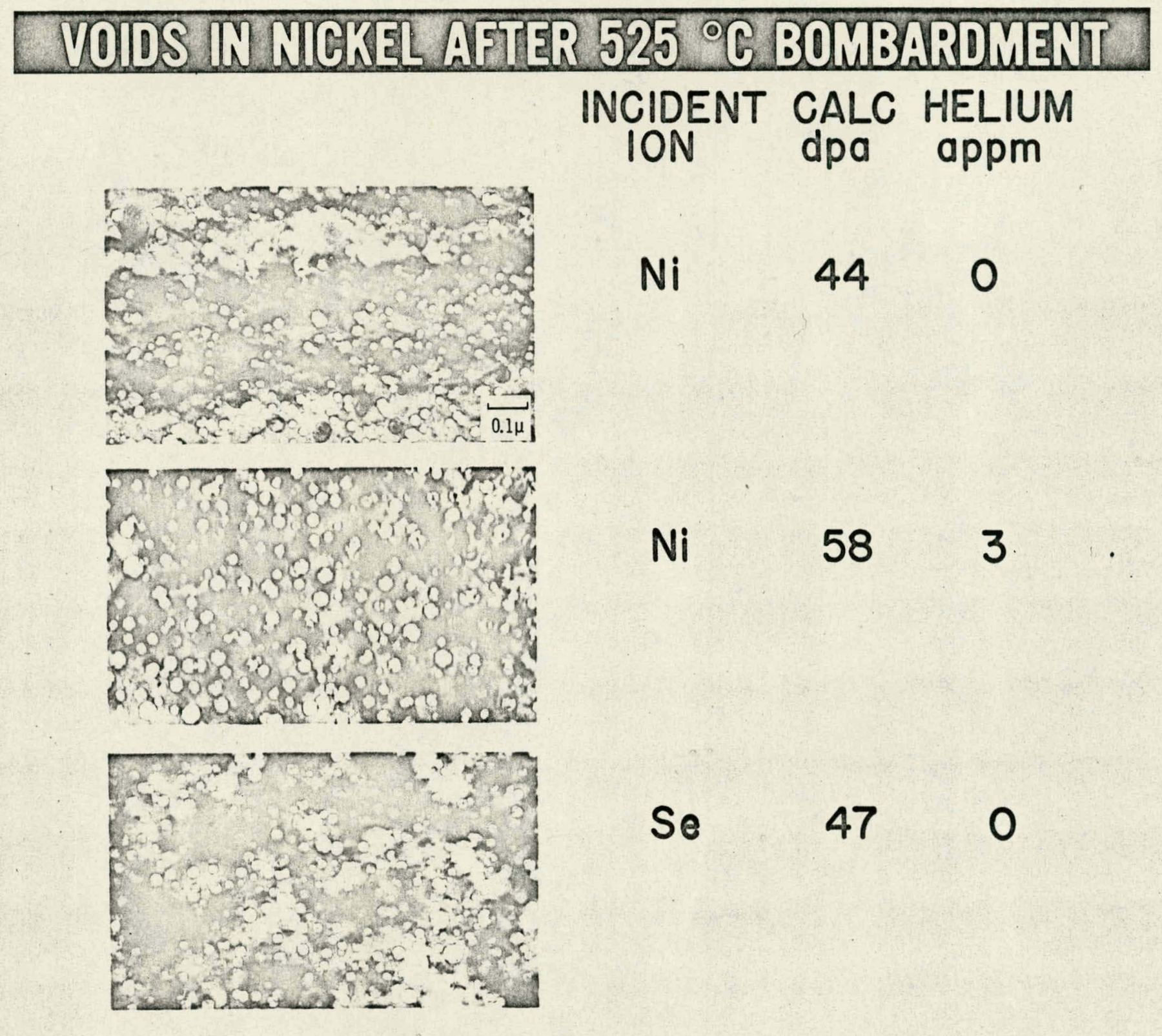




\section{SWELLING IN NICKEL AFTER BOMBARDMENT AT $525^{\circ} \mathrm{C}$}

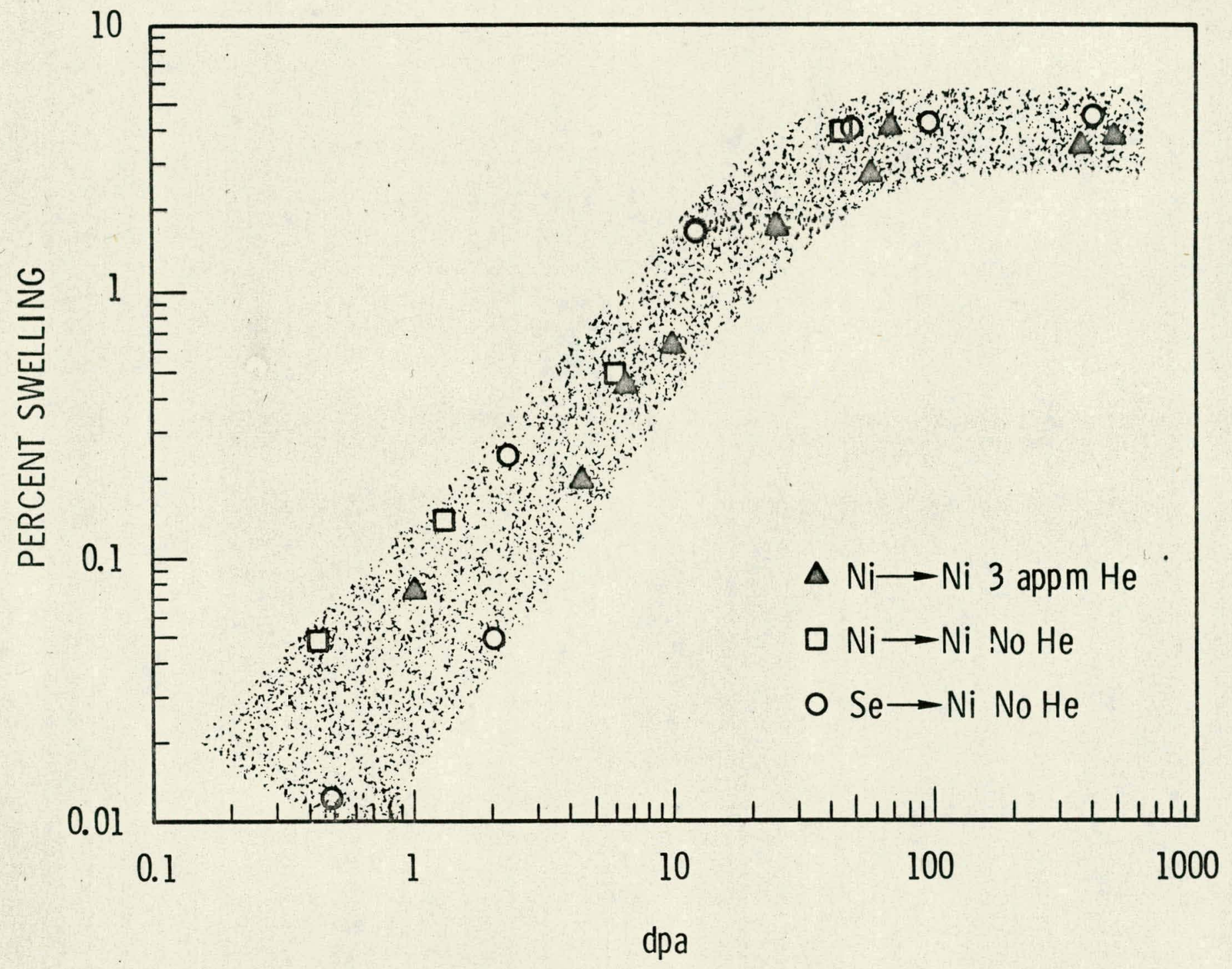


VOIDS IN SE BOMBARDED NICKEL 400 DISPLACEMENTSIATOM AT $525^{\circ} \mathrm{C}$
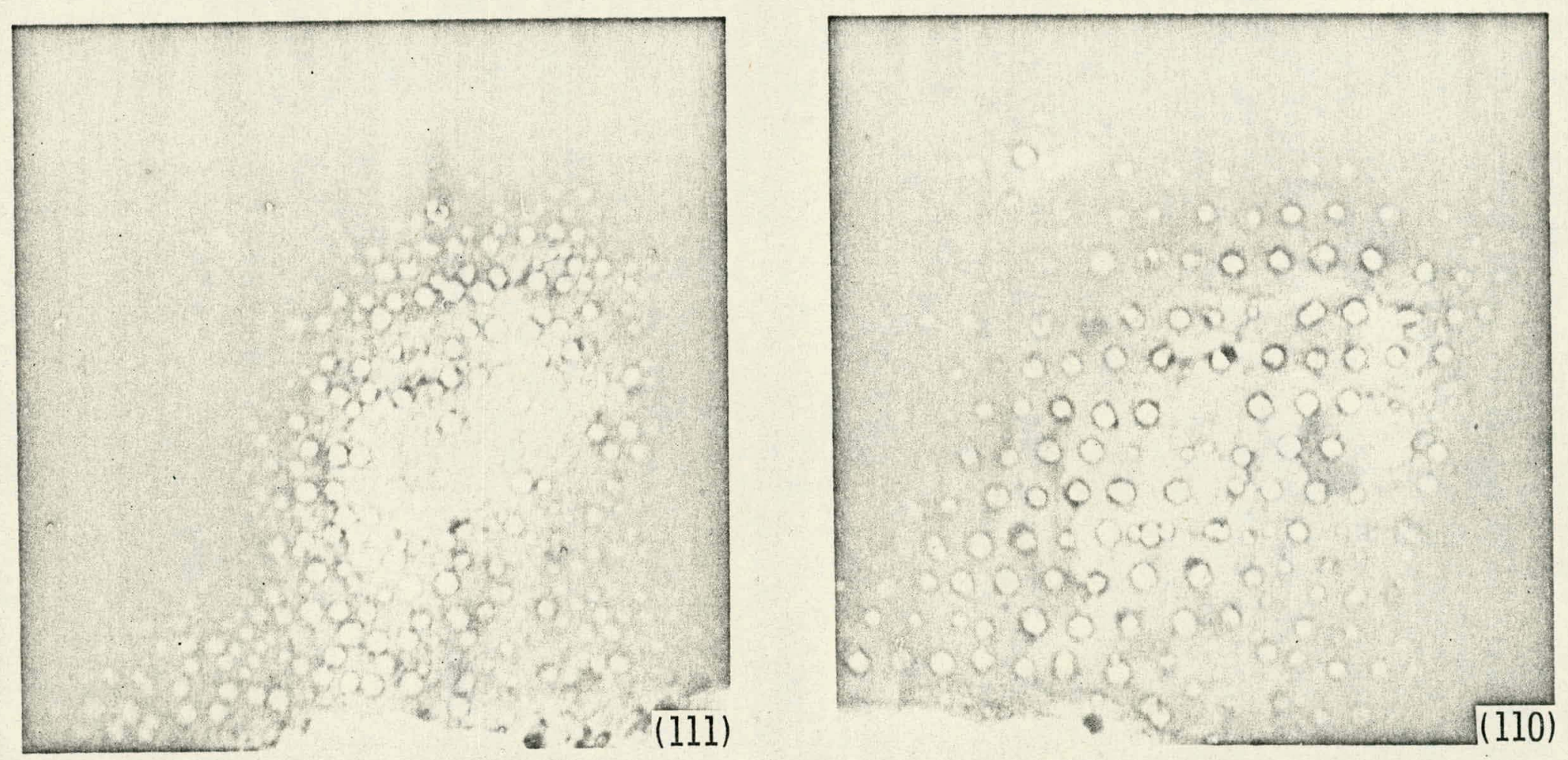

(a)
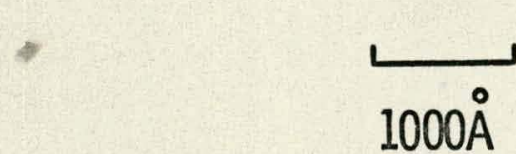

(b) SAME AS a) EXCEPT FOR ORIENTATION $1000 \AA$ 


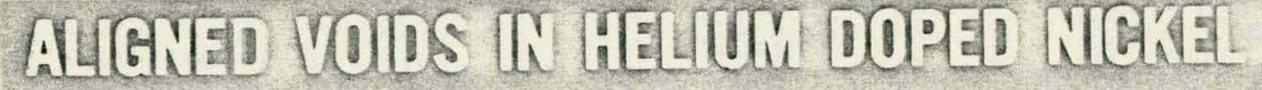 360 dise at $525^{\circ}$ of}

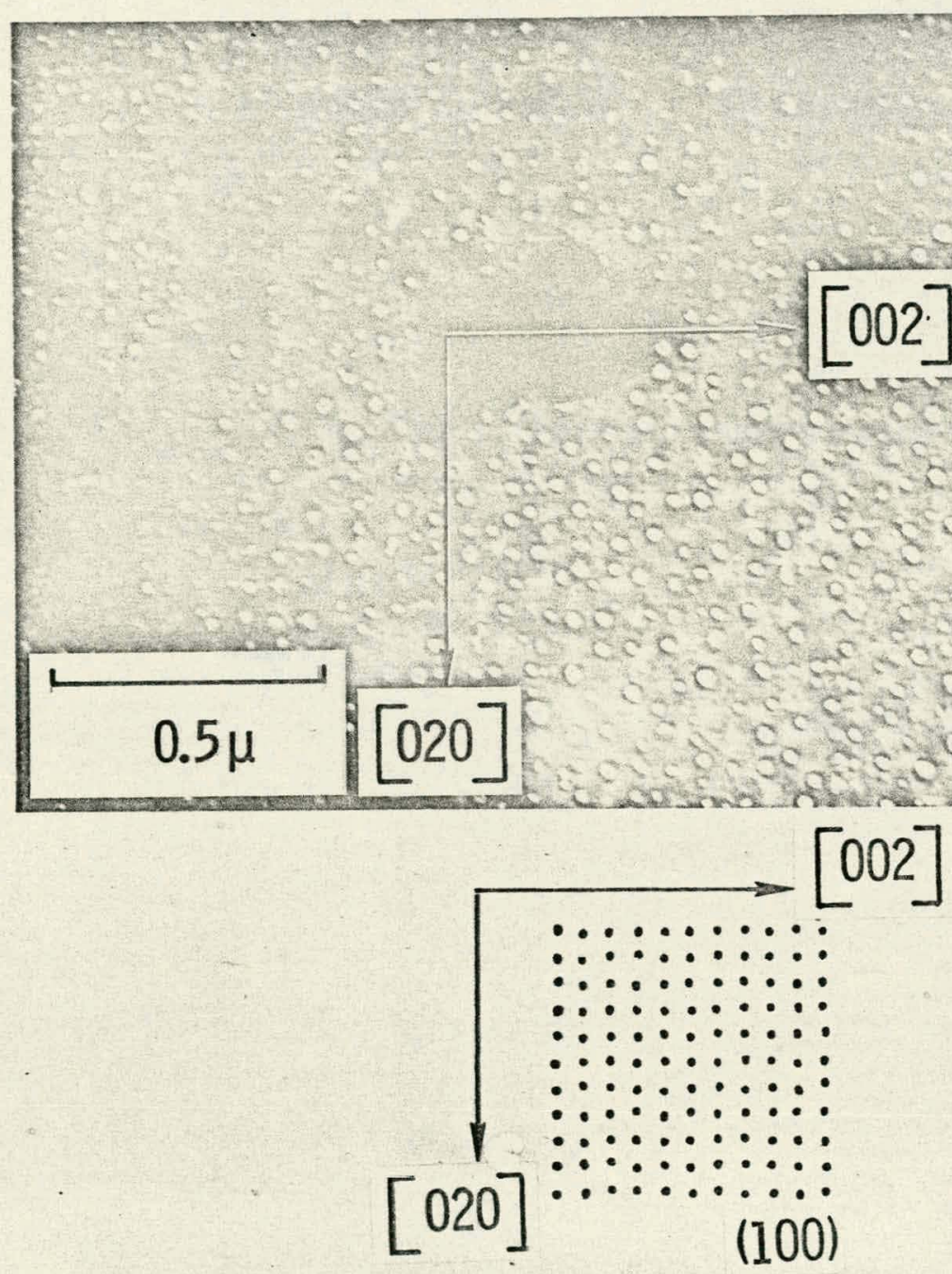




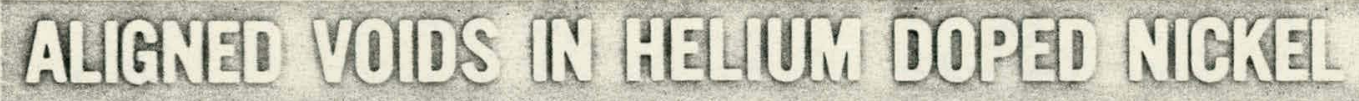 360 dipe At $5255^{\circ}$ of}
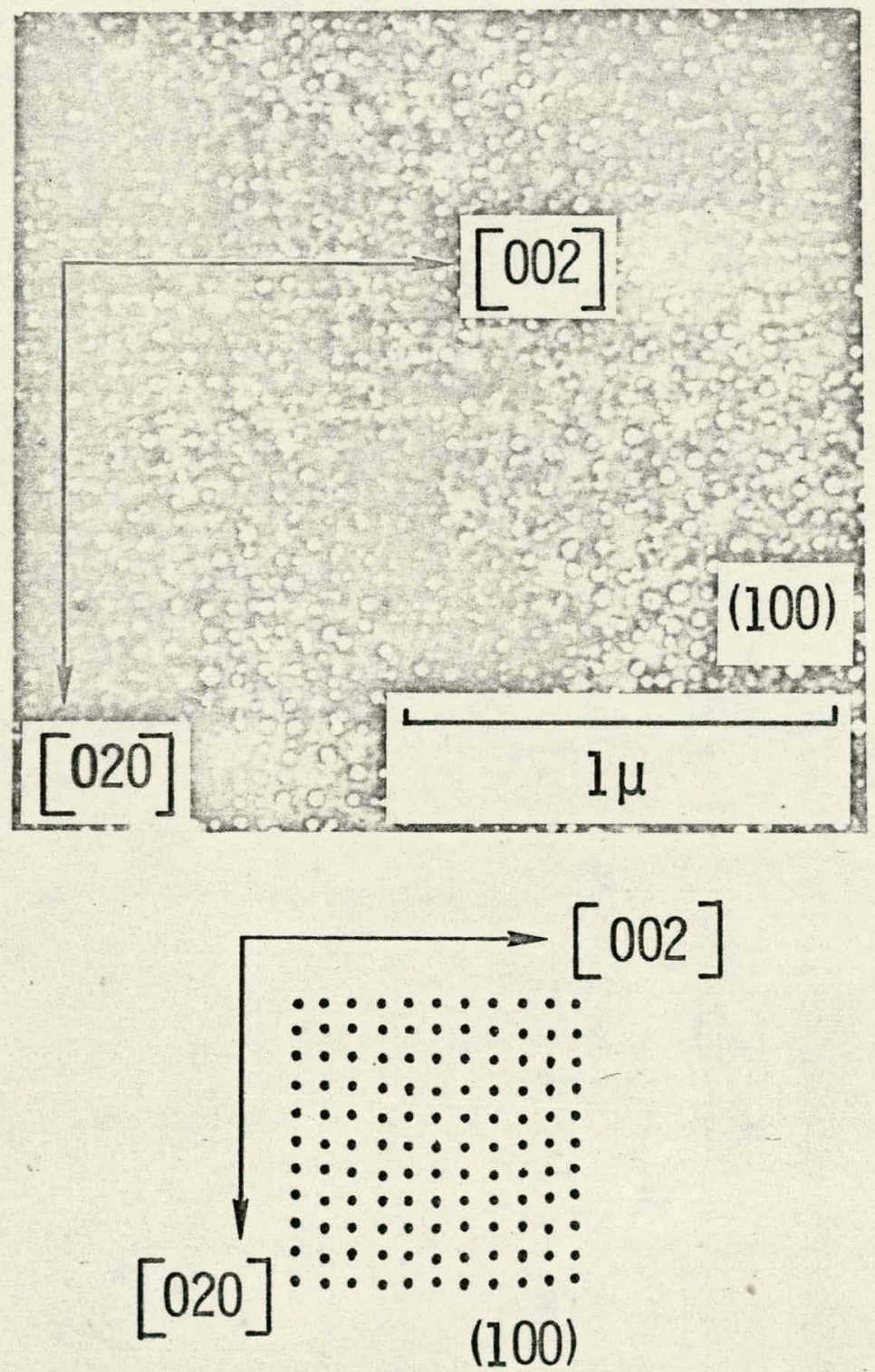

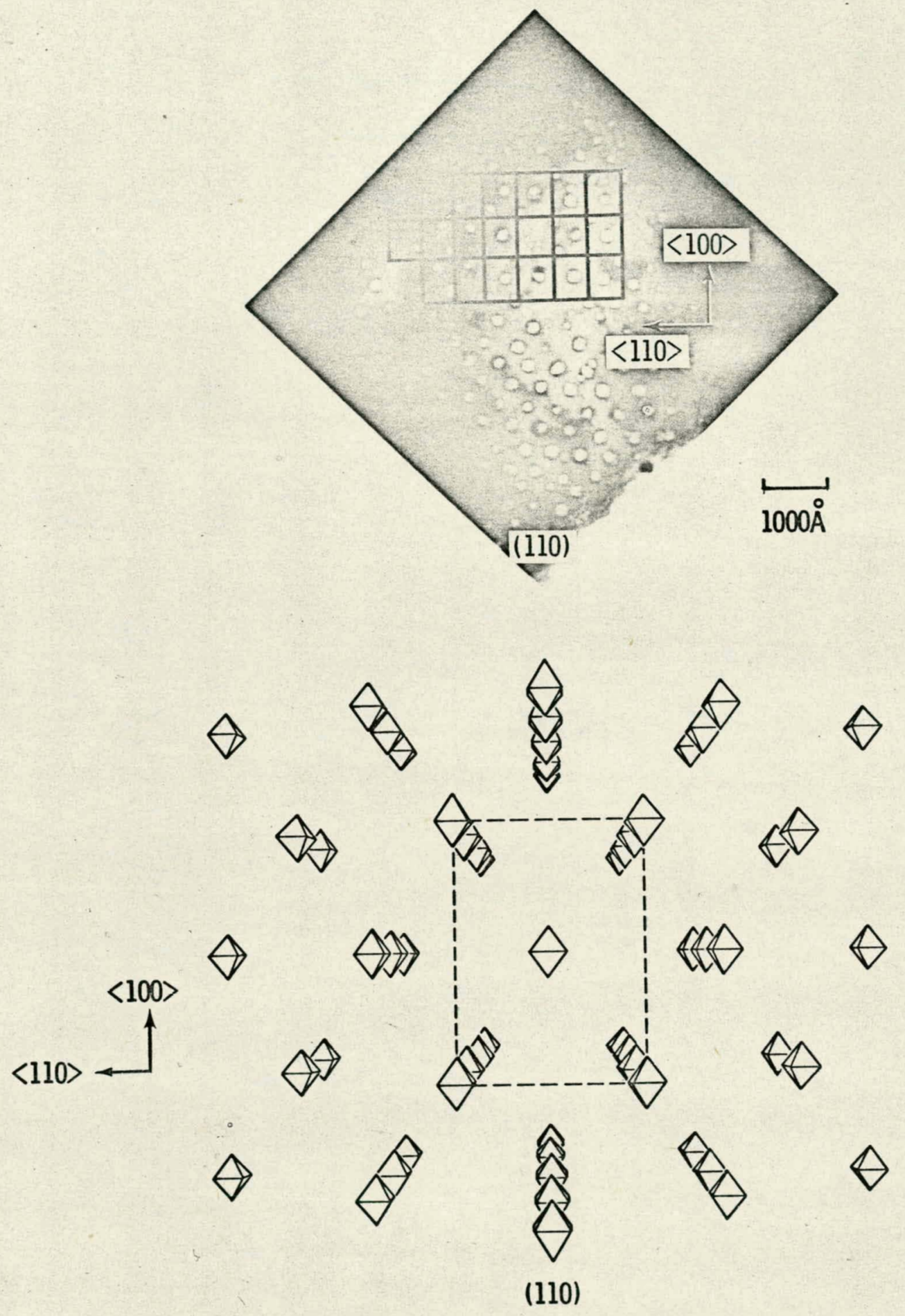

FACE CENTERED CUBIC SUPERLATTICE OF VOIDS IN NICKEL 


\section{NOIDS TN MO \& No}
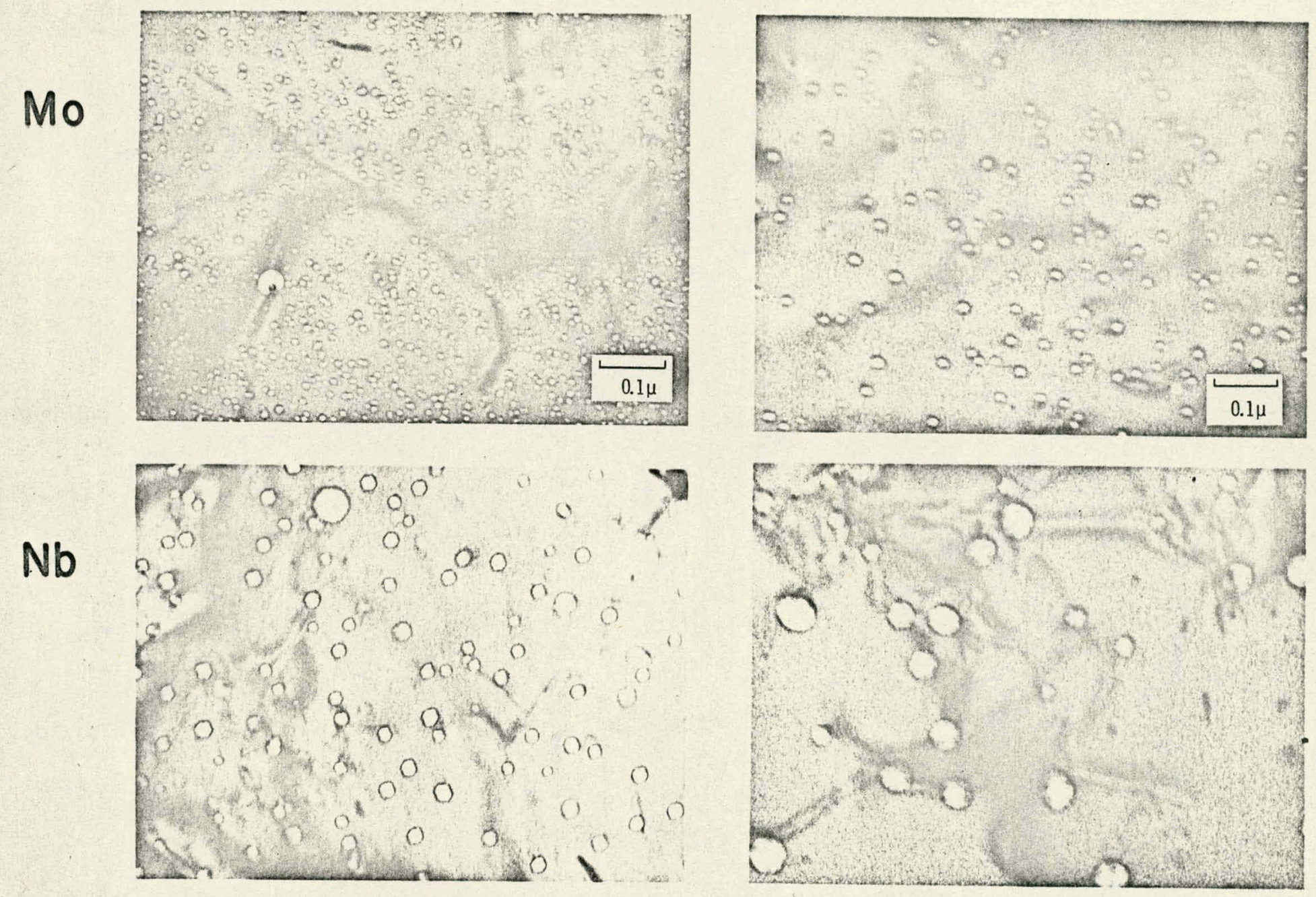

$900^{\circ} \mathrm{C}$

\section{$1000^{\circ} \mathrm{C}$}




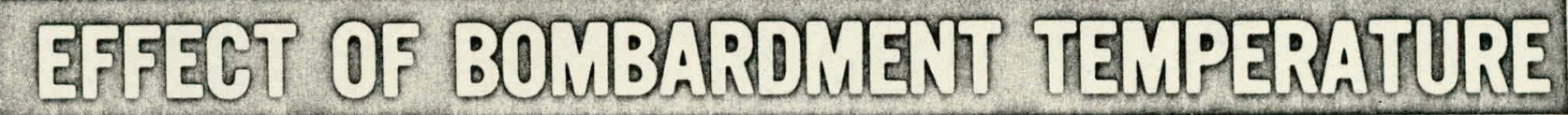 \\ ON NOIDS MN TIZM}

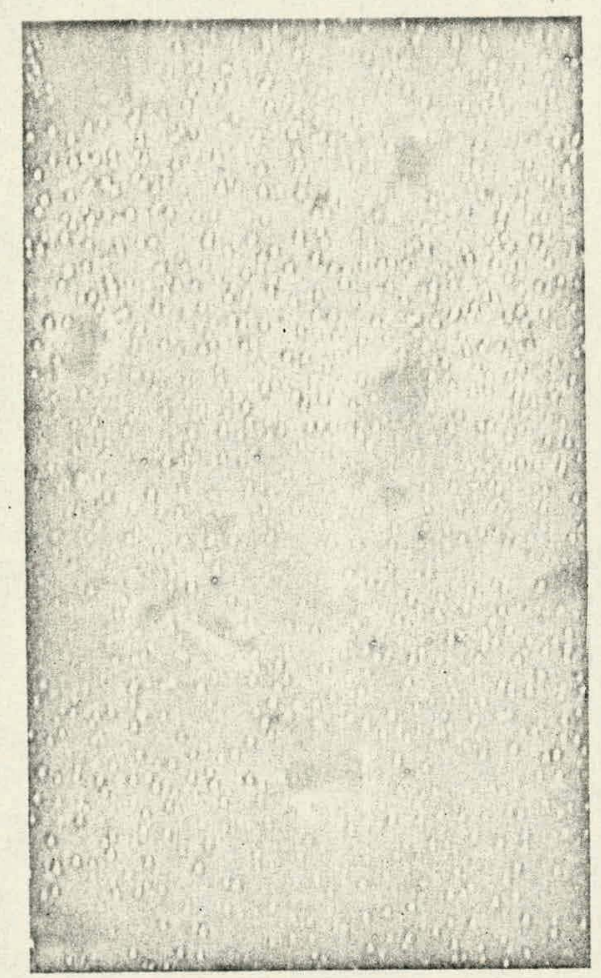

$800^{\circ} \mathrm{C}$

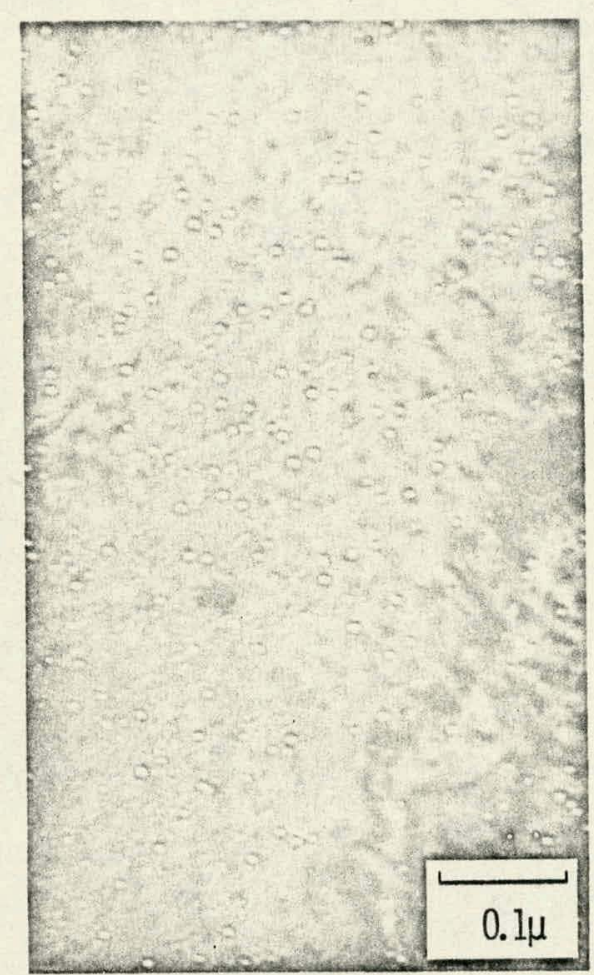

$900^{\circ} \mathrm{C}$

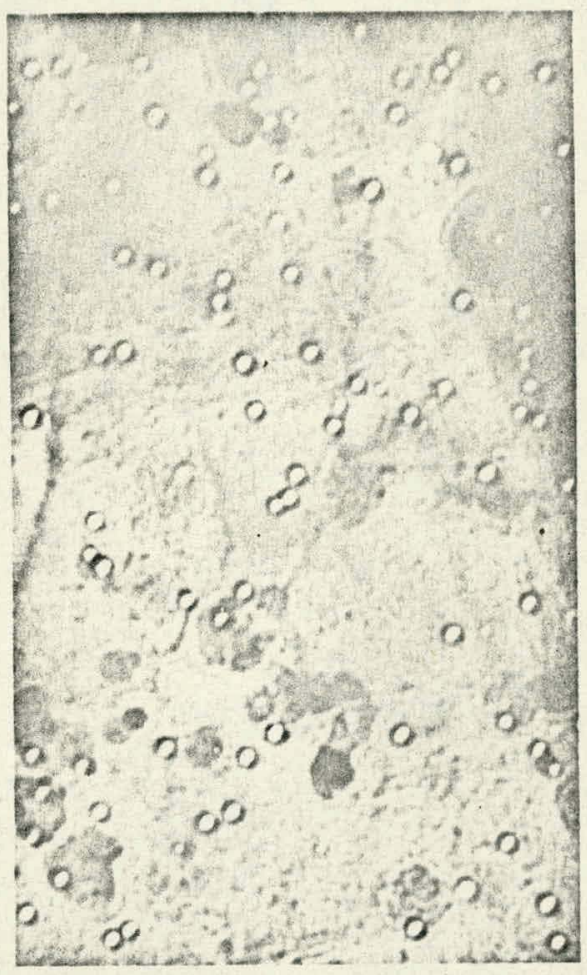

$1000^{\circ} \mathrm{C}$ 


\section{VOID INDUCED SWELLING}

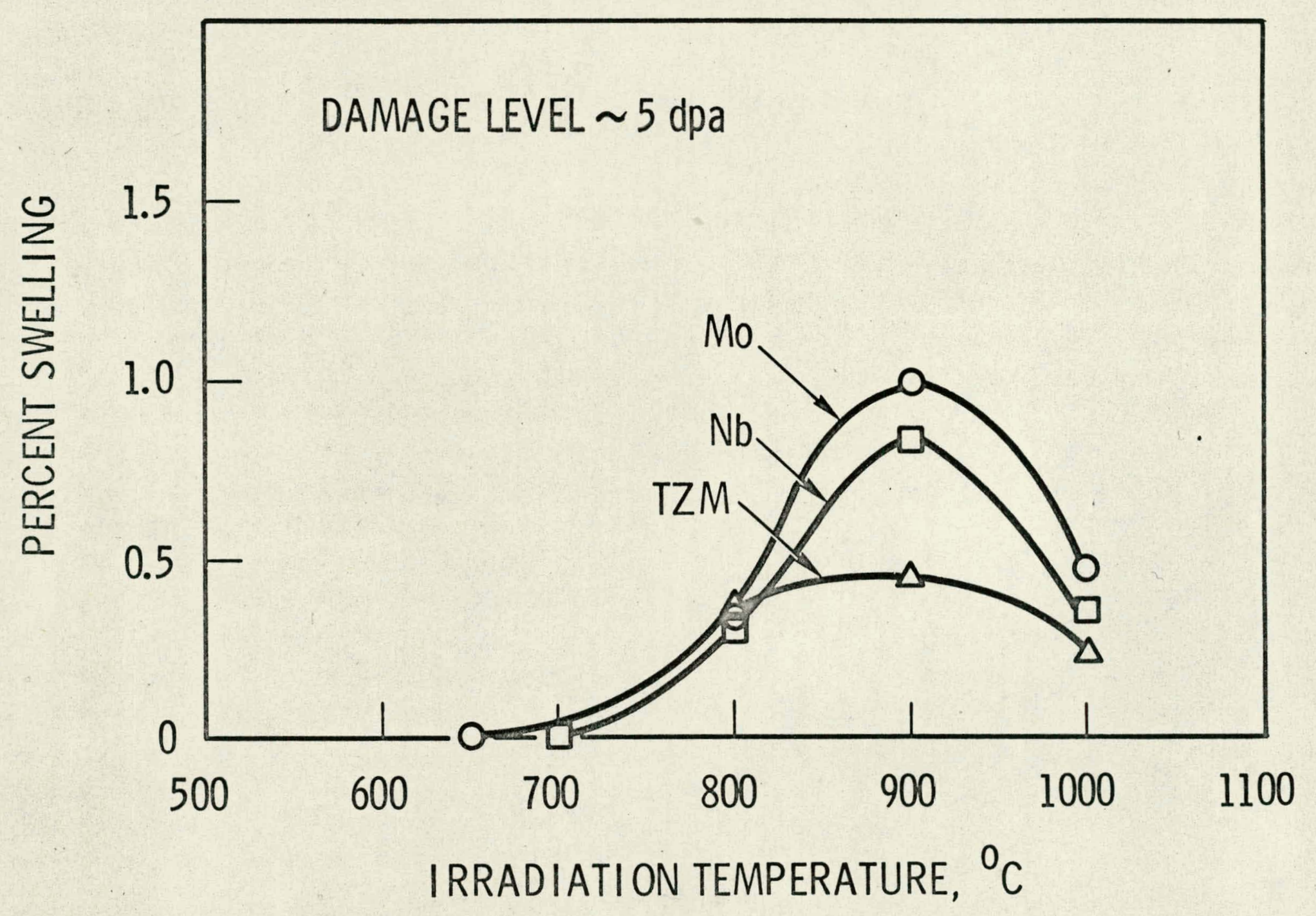






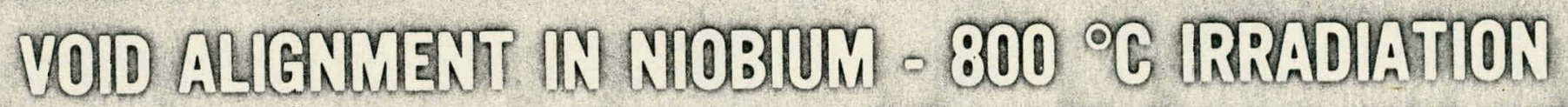

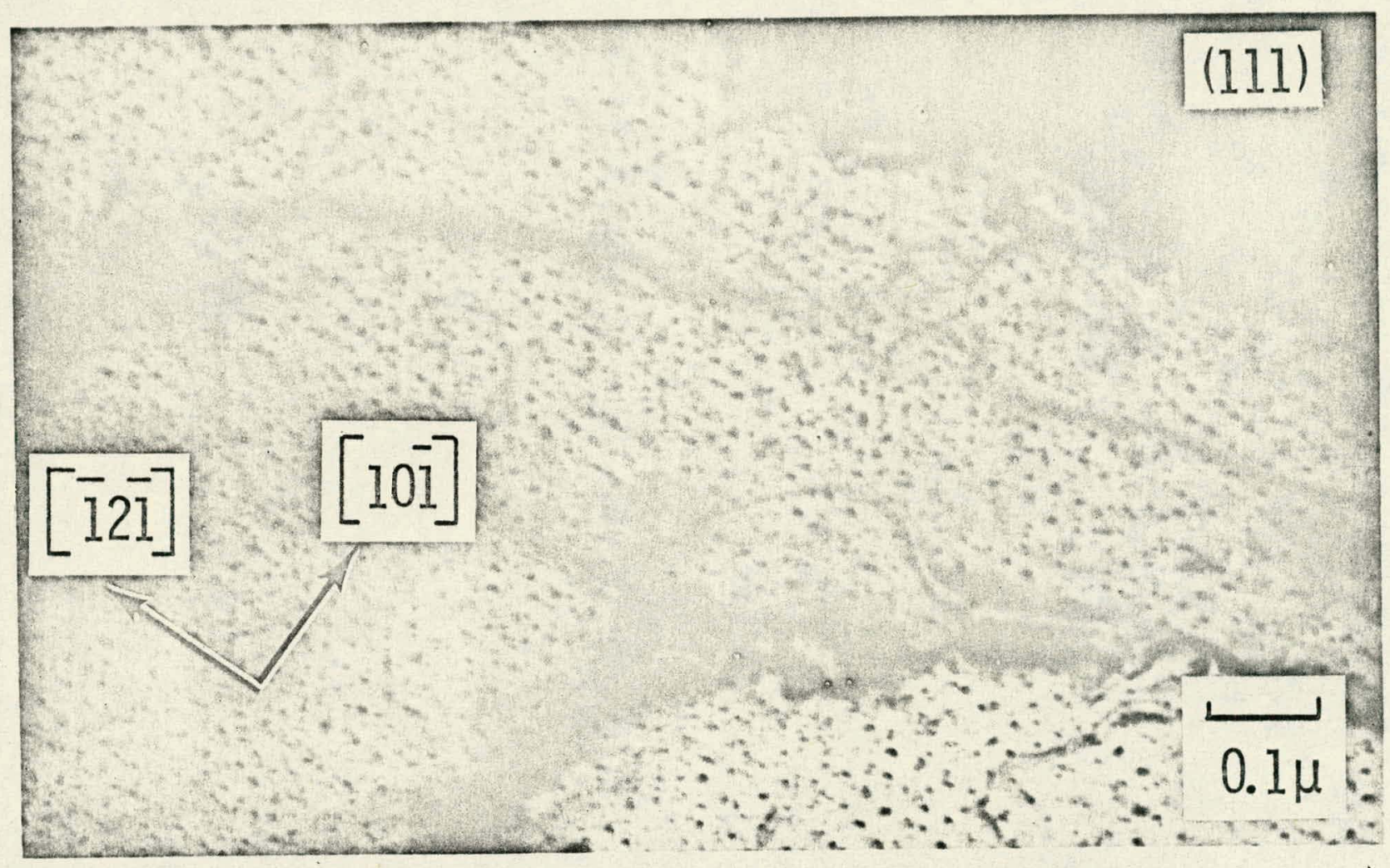




\section{SWELLING IN NEUTRON IRRADIATED Ni}

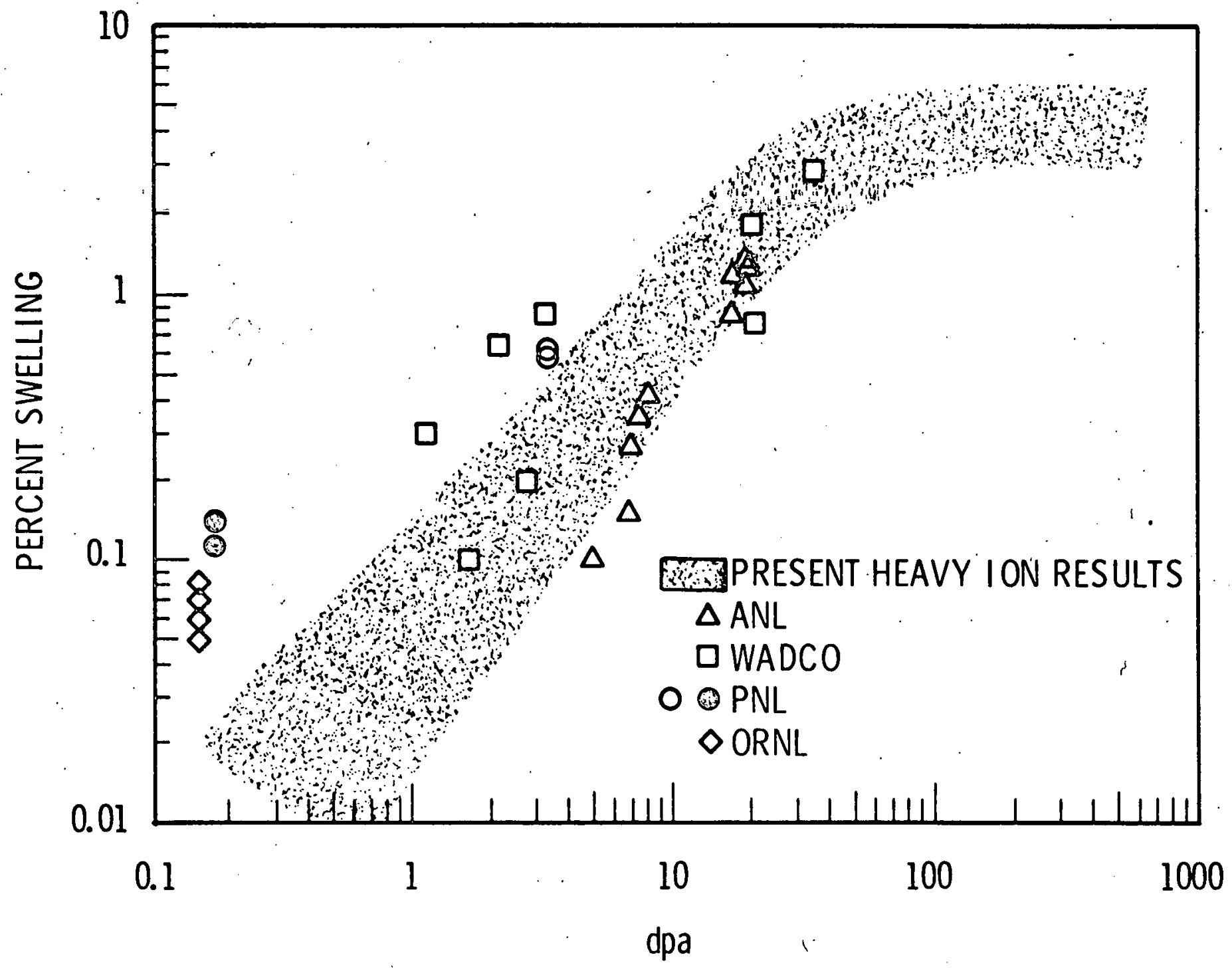

